\title{
Seasonal Characteristics of New Particle Formation and Growth in Urban Beijing
}

\section{Deng, Chenjuan}

2020-07-21

Deng , C , Fu , Y, Dada , L, Yan , C , Cai , R , Yang , D , Zhou , Y, Yin , R , Lu , Y , Li , X , Qiao , X , Fan , X, Nie , W , Kontkanen , J , Kangasluoma , J , Chu , B , Ding , A , Kerminen , V-M , Paasonen , P , Worsnop, D R, Bianchi , F , Liu , Y, Zheng , J, Wang , L, Kulmala , M \& Jiang , J 2020 , ' Seasonal Characteristics of New Particle Formation and Growth in Urban Beijing ' , Environmental Science \& Technology , vol. 54 , no. 14 , pp. 8547-8557 . https://doi.org/10.1021/acs

http://hdl.handle.net/10138/332501

https://doi.org/10.1021/acs.est.0c00808

acceptedVersion

Downloaded from Helda, University of Helsinki institutional repository.

This is an electronic reprint of the original article.

This reprint may differ from the original in pagination and typographic detail.

Please cite the original version. 


\section{Seasonal eharacteristies $\underline{C h a r a c t e r i s t i c s ~ o f ~ n e w ~ p a r t i e l e ~ f o r m a t i o n ~ N e w ~ P a r t i c l e ~ F o r m a t i o n ~}$} and growthGrowth in urban Urban Beijing

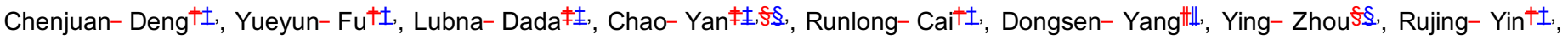

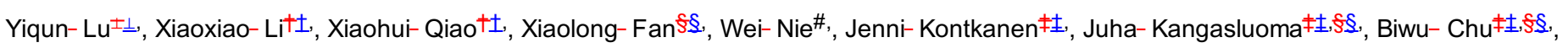

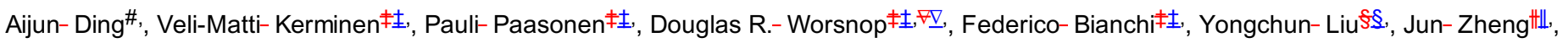
Lin- Wang ${ }^{ \pm \perp}$, Markku- Kulmala ${ }^{*}$, 扗, $\S$, , Jingkun- Jiang ${ }^{* *}, \pm 土$,

\#__ State Key Joint Laboratory of Environment Simulation and Pollution Control, School of Environment, Tsinghua University, 100084 Beijing China

垹- Institute for Atmospheric and Earth System Researeh/Physies, Research Physics, Faculty of Science, University of Helsinki, 00014 Helsinki, Finland

f__ Aerosol and Haze Laboratory, Beijing Advanced Innovation Center for Soft Matter Science and Engineering, Beijing University of Chemical Technology, 100029 Beijing, China

\#- Collaborative Innovation Center of Atmospheric Environment and Equipment Technology, Nanjing University of Information Science and Technology, 210044 Nanjing, China

\pm - Shanghai Key Laboratory of Atmospheric Particle Pollution and Prevention (LAP3), Department of Environmental Science and Engineering, Fudan University, Shanghai200433 Shanghai, China

\#_ Joint International Research Laboratory of Atmospheric and Earth System Sciences, School of Atmospheric Sciences, Nanjing University, 210023 Nanjing, China

\#- Aerodyne Research Inc., Billerica, Massachusetts 01821, USA United States

*- email:Email: markku.kulmala@helsinki.fi.

**-email:Email: jiangjk@tsinghua.edu.cn.

22-06-2020

\section{Abstract}

Understanding the atmospheric new particle formation (NPF) process within the global range is important for revealing the budget of atmospheric aerosols and their impacts. We investigated the seasonal characteristics of NPF in the urban environment of Beijing. Aerosol size distributions down to $\sim \underline{-1} \mathrm{~nm}$ and $\mathrm{H}_{2} \mathrm{SO}_{4}$ concentration were measured during $2018-2019-2018-2019$. The observed formation rate of $1.5 \mathrm{~nm}$ particles $\left(J_{1.5}\right)$ is significantly higher than those in the clean environment, e.g., Hyytiälä; Hyytiälä, whereas the growth rate is relatively lower. Both $J_{1.5}$ and NPF frequency in urban Beijing showed a clear seasonal variation with maxima in winter and minima in summer, while the observed growth rates were generally within the same range around the year. We show that ambient temperature is a governing factor driving the seasonal variation of $J_{1.5}$. In contrast, the condensation sink showed no significant seasonal variation during the NPF periods and the daily maximum $\mathrm{H}_{2} \mathrm{SO}_{4}$ concentration was slightly higher in summer than thatin winter. In all four seasons, condensation of $\mathrm{H}_{2} \mathrm{SO}_{4}$ and $\left(\mathrm{H}_{2} \mathrm{SO}_{4}\right)_{\pi \underline{n}}(\text { amine })_{\mathbb{n} \underline{n}}$ clusters contributes significantly to the growth rates in the sub-3 nm size range, whereas it is less important for the observed growth rates of particles above $3 \mathrm{~nm}$. Therefore, other species are always needed for the growth of larger particles. 


\section{Keywords}

New Particle Formationnew particle formation; Growthgrowth; seasonal variaSeasonal Variationtion; Femperature Influencetemperature influence

\section{1.-. Introduction}

TOC ArtPlace Figure 1 HerePlace Figure 2 HerePlace Figure 3 HerePlace Figure 4 HerePlace Figure 5 HerePlace Figure 6 HerePlace Figure 7 HereSupplementary Information Corresponding AuthorJingkun JiangMarkku KulmalaAtmospheric new particle formation (NPF) refers to the conversion from gaseous precursors to new particles. It is ubiquitous and contributes majorly to the global aerosol populationpopulation. ${ }^{1-3}$ - Once growing past certain sizes, the newly formed particles can be activated as the cloud condensation nuclei $(\mathrm{CCN})$ and thusand, thus, influence cloud formation and global elimateclimate. ${ }^{4,5_{-}}$It is estimated that around half of global $\mathrm{CCN}$ in the lower troposphere are derived from atmospheric NPFNPF ${ }^{5,6_{-}}$

To understand the NPF phenomenon within the wide global range, many field studies were conducted throughout the world in both pristine and polluted envirenmentsenvironments. ${ }^{1,7,8}$ - Different from relatively clean environments, the concentration of pre-existing aerosols is high in polluted environments, which suppresses NPF by acting as a sink for both condensable vapors and newly formed particles. ${ }^{9-11}$ - Despite the strong suppression by the high aerosol loading in polluted environments, intensive NPF events have still been frequently observed in these environmentsenvironments. ${ }^{8,11-15_{-}}$

Seasonal characteristics of NPF have been explored in urban BeijingBeijing. ${ }^{16,17}$ - However, due to limitations in applied instruments in these long-term studies, there is practically no information about key precursors for new particle formation $\left(\right.$ e.g., $\left.\mathrm{H}_{2} \mathrm{SO}_{4}\right)$ and size distributions of sub-3 nm particles. Although the $\mathrm{H}_{2} \mathrm{SO}_{4}$ concentration was measured in two short-term field campaigns in urban Beijing ${ }^{11,18}$ and its daily maximum concentration ranged from $-10 \sim 10^{5}$ to $1.9 * x 10^{7} \mathrm{~cm}-\underline{3}$, the seasonal variation of the $\mathrm{H}_{2} \mathrm{SO}_{4} \mathrm{concentration}^{2}$ Beijing has not yet been reported. tong-term The long-term size distribution data for sub-3 nm particles has also been missing from previous studies in Beijing and even rarely reported in other environments. As shown in a recent studystudy, ${ }^{19}$, previously reported particle formation rates for urban Beijing (inferred from large sizedlarge-sized particles) were underestimated and sub-3 nm particle size distributions $\underline{\text { (PSDs) }}$ are needed to accurately quantify these rates.

When evaluating the particle formation rate from measured data, underestimating coagulation scavenging can lead to significant underestimation of the particle formation rate, especially for polluted environments and controlled chamber studies having a strong coagulation effect. Cai and Jiang ${ }^{19}$ found that the commonly-used-commonly used formulae underestimate the formation rate of $1.5 \mathrm{~nm}$ particles in urban Beijing, so they derived an improved formula with a more accurate treatment of the coagulation effect. Also, due to the underestimation of the coagulation effect, new particle formation rates from CLOUD (Cosmiesthe Cosmics Leaving OUtdoor Broplets) Droplets (CLOUD) chamber studies on sulfuric acid-dimethylamine (DMA) nucleation were later corrected to be a factor of 10 faster than previously published resultsresults. ${ }^{20}$ - In addition, Cai et al. ${ }^{21}$ showshowed that neglecting coagulation scavenging can result in overestimation when evaluationg evaluating the particle growth rate from the measured data.

Although clear seasonal variations in the frequency of NPF events hashave been observed in urban BeijingBeijing ${ }^{16,17}$, the factors governing these seasonal variations femainsremain to be revealed. The concentrations of gaseous precursors and the coagulation scavenging effect of the pre-existing aerosols are important factors that govern the occurrence and the intensity of NPF. Their synergetic effect on NPF can be evaluated using dimensionless parameters such as $L^{22}$ or $L_{F[-\underline{-}}{ }^{23}$ - Using $L_{\mp[\underline{[}}$, Cai et al. ${ }^{11}$ showed that the pre-existing aerosol surface area governs the occurrence of NPF in Beijing in a short-term campaign. In addition to pre-existing aerosols and $\mathrm{H}_{2} \mathrm{SO}_{4}$ concentration, other factors, such as ambient temperature and concentration of base molecules, may also affect NPF. Recently, Cai et al. ${ }^{24}$ showed that the NPF events in urban Beijing are dominated by $\mathrm{H}_{2} \mathrm{SO}_{4}$-amine nucleation and proposed a new parameter, l, for predicting the occurrence of NPF in environments governed by $\mathrm{H}_{2} \mathrm{SO}_{4}$-amine nucleation. Factors governing the seasonal variation of NPF in urban Beijing can be explored with the help of this new parameter.

In addition to the formation of new particles, the subsequent growth of these particles and itstheir seasonal characteristics are also of great importance. The particle growth rates in the $3-25 \underline{3-25} \mathrm{~nm}$ size range were reported to be slightly higher in summer than in other seasons in 
BeijingBeijing. ${ }^{17}$ - However, the seasonal variation of the observed growth rates in different size ranges has not yet been reported in urban Beijing, especially in the sub-3 nm size range. As a condensable vapor, $\mathrm{H}_{2} \mathrm{SO}_{4}$ contributes to the particle growth; however, its contribution usually decreases with an increasing particle sizesize. ${ }^{25-27}$ - In addition to $\mathrm{H}_{2} \mathrm{SO}_{4}$, small acid-baseacid-base clusters can also contribute to the particle growth, especially in the sub- $3 \mathrm{~nm}$ size fangerange. ${ }^{28_{-}}$

In this study, we report the results of long-term field measurements conducted in urban Beijing during 2018-2019,2018-2019, including the measurements of particle size distribution down to $\sim \underline{-1} \mathrm{~nm}$ and $\mathrm{H}_{2} \mathrm{SO}_{4}$ concentration. We focus on seasonal characteristics of new particle formation rates and growth rates and explore factors governing the observed seasonal characteristics. We also compare the characteristics of NPF in urban Beijing with observations in other atmospheric environments.

\section{2-. Methods}

\section{1-..Measurements}

The observation site is located on the top of a five-floor building at Beijing University of Chemical Technology (West Campus), Beijing. The sampling inlets are located $-20 \sim 20 \mathrm{~m}$ above the ground and $\sim 150 \sim 150 \mathrm{~m}$ to the southwest of a road. The Third Ring Road is $\sim 550 \sim 550 \mathrm{~m}$ to the east of the sitesite, and as a major road, the traffic is often busy. More details on the site can be found in the study reported by Lu et al. ${ }^{29}$ and Zhou et al. ${ }^{30}$ - There are no significant stationary emission sources nearby. However, the emission from vehicles may influence the measured aerosols and gaseous pollutants.

The wide-range size distributions of $1 \mathrm{~nm}-10 \mu \mathrm{m} n \mathrm{~nm}-10 \mu \mathrm{m}$ particles were measured using a prototype diethylene glycol scanning mobility particle spectrometer (DEG-SMPS; $1-7.5 \underline{1-7.5} \mathrm{~nm})^{31,32}$ and a particle size distribution system (PSD; $\left.3 \mathrm{~nm}-10 \mu \mathrm{m}\right) \underline{\mathrm{nm}-10 \mu m)}{ }^{33-}$ The DEGSMPS was sampled through the northern window of the observation room. The aerosols entering the DEG-SMPS were sampled using a core sampling method with $\sim 100 \%$ 100\% sampling efficiencyefficiency. ${ }^{34}$ - The DEG-SMPS was equipped with a soft X-ray neutralizer (TSI Inc., model 3088) for aerosol charging and a miniature cylindrical differential mobility analyzer (mini-cyDMA) ${ }^{32}$ for sub-10 nm aerosol classification. Downstream of the mini-cyDMA, the DEG-UCPC was modified from a commercialized UCPC (TSI Inc., model 3776). The temperatures of the saturator and the condenser of the DEG-UCPC were $71{ }^{\circ} \mathrm{C}$ and $20^{\circ} \mathrm{C},{ }^{\circ} \mathrm{C}$, respectively. The flow rates through the DEG-UCPC capillary and the saturator were 0.25 and $0.75 \mathrm{tmin} \cdot \mathrm{min}-11$, respectively. A commercialized CPC was used to count the particles in the downstream of DEG-UCPC. The DEG-SMPS was calibrated four times a year using a homemade calibration systemsystem. ${ }^{31}$ - The PSD inlet was deployed downstream of a $\mathrm{PM}_{10}$ impactor on the roof. The relative humidity was conditioned to be below 40\% using a Nafion dryer (Perma Pure, MD-700-24F-3)MD-700-24F-3) on the sampling line. The PSD consists of a TSI aerodynamic particle sizer (TSI Inc., model 3321) and two parallel SMPSs equipped with a TSI nanoDMA (TSI Inc., model 3085) and a TSI longDMA (TSI Inc., model 3081), respectively. The time resolution for particle size distribution measurement was 5 min.

The $\mathrm{H}_{2} \mathrm{SO}_{4}$ concentration was measured by a chemical ionization-atmospheric interface-time of flightinterface-time-of-flight mass spectrometersspectrometer (Cl-APi-ToF, or CIMS; Aerodyne Research Inc.) equipped with a nitrate chemical ionizationionization. ${ }^{35-37}$ Before Apr.April 14, 2018, the $\mathrm{H}_{2} \mathrm{SO}_{4}$ concentration was measured by a long time-of-flight mass spectrometer (Cl-APi-LToF) and after that it was measured by a high-resolution time-of-flight mass spectrometer (Cl-APi-HToF). Ambient air was taken into the CIMS through the north window. The sampling line was straight stainless-steel tubing with an outer diameter of 3/4 ineh.in. Before and after Apr.April 14, the length of the sampling line was $1.6 \mathrm{~m}$ and $1.4 \mathrm{~m}$, respectively, and the sampling flow rate was $8.8 \mathrm{t} \cdot \mathrm{min}^{-1}$ and $8.5 \mathrm{t} \cdot \mathrm{min} \underline{\underline{L} \cdot \mathrm{min}^{-}-1} \underline{1}$, respectively. The sampling configurations during these two periods were similar withto those previously described inby Lu et al. ${ }^{29_{-}} \mathrm{The}_{2} \mathrm{SO}_{4}$ concentration was calibrated using a homemade calibration systemsystem. ${ }^{38}$ - The calibration system produces $\mathrm{H}_{2} \mathrm{SO}_{4}$ from the oxidation of $\mathrm{SO}_{2}$ by $\mathrm{OH}$ radicals. The transmission efficiency of the spectrometer was measured by adding different perfluorinated acids in amounts sufficient to deplete $\mathrm{NO}^{3}-3{ }_{-}-$The time resolution for the $\mathrm{H}_{2} \mathrm{SO}_{4}$ concentration was 5 min.

The meteorological data, including the temperature, ambient pressure, relative humidity, wind speedspeed, and wind direction, were measured by a local weather station (Vaisala, AWS310). Amine concentration was measured using a modified ToF-CIMS (Aerodyne

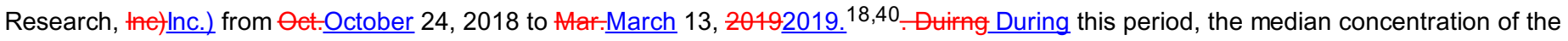
most abundant amine species, dimethylamine (DMA), was 2.7 ppt. The time resolution of the meteorological data and the amine concentration was $5 \mathrm{~min}$. 
The long-term field measurement started from Jan-January 2018. In this study, we used the aerosol size distribution data on a total of 234 days in 2018 (Jan. 16-Apr. (January 16-April 10, Apr. 29-May-April 29-May 17, May Z2-Dec. 22-December 26) and a total of 48 days in 2019 summer (June 1-Aug.1-August 31), covering winter (Dec. - Feb.), (December-February), spring (Mar. - May), (March-May), summer (Jun. Aug.) (June-August), and autumn (Sep. Nov.).(September-November). $\mathrm{The}_{2} \mathrm{SO}_{4}$ concentration data were available on 131 days in 2018 (Jan. 23-Apr. (January 23-April 10, Oet. 20-Dec. October 20-December 26) and 67 days in 2019 summer (Jun. 1 Aug.(June 1-August 13). Note that the data from the summer of 2019 were used to complement the analysis of NPF seasonal characteristics in urban Beijing. Đata-The data from the summer of 2018 were only used to evaluate NPF frequencies.

\section{2-. Data analysis. Analysis}

During these measurement periods, we classified all of the days into NPF days, undefined days, and non-NPF days. The classification criteria and examples are described in the Supplementary Information (SI).Supplementary Information (SI).

The particle formation rate quantifies the growth flux through a certain particle diameter, which characterizes the intensity of NPF. In this study, the particle formation rate was calculated using a balance formula by Cai and Jiang Jiang. ${ }^{19}$, which improves the estimation of coagulation scavenging in the presence of high aerosol loadings:

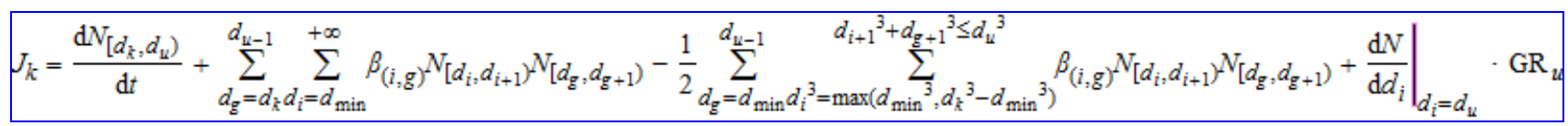

HereHere, $J_{k \underline{k}}$ is the particle formation rate at size $d_{k \underline{k},} \mathrm{~cm}^{3}-\underline{-s}-11$, with $d_{k \underline{k}}$ chosen to be $1.5 \mathrm{~nm}$ in this study, m; $d_{\mathrm{t} \underline{\underline{u}}}$ is the upper size limit of the targeted aerosol population, $\mathrm{m} ; d_{\mathrm{min}}$ is the smallest particle size detected by particle size spectrometers, $\mathrm{m} ; N_{\left\lfloor d_{k}, d_{u}\right)}$ is the number concentration of particles from size $d_{k \underline{k}}$ to $d_{t \underline{u} \underline{u}}, \mathrm{~cm}-\underline{3} \underline{3} ; d_{\underline{i}}$ represents the lower limit of the $\underline{i t h}^{\text {th }}$ size bin, m; $\beta \underline{\beta}(i, g)(i, g)$ is the coagulation

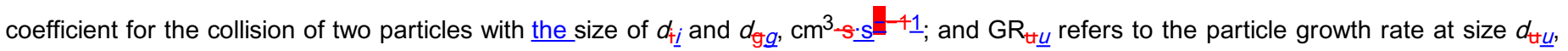
nm.hnm.h-1 -1 .

The particle growth rate, GR, was obtained using the log-normal distribution function methodmethod, which tracks the temporal variation of the representative diameterdiameter. ${ }^{41}$ - The growth rates in various particle size ranges, $\mathrm{GR}_{1-3}, \mathrm{GR}_{3-7} \underline{3-7}, \mathrm{GR}_{7-157-15}$, and $\mathrm{GR}_{15-25} \underline{15-25}$ ․ were calculated separately, where the subscripts indicate the size range (see the example given in Figure S2 in the S1).Supporting Information $(S I)$ ). Note that since the contribution of coagulation scavenging was not excluded, the obtained particle growth rates are apparent growth rates rather than growth rates resulting solely from the condensation onto individual particlesparticles. ${ }^{42}$.

The coagulation scavenging of particles was characterized using the condensation sink (CS)(CS), which was calculated using Equationeqs $\mathrm{S} 1$ and Equations2 in the SISI. ${ }^{41}$ - The influences of temperature and relative humidity on the diffusivity of $\mathrm{H}_{2} \mathrm{SO}_{4}$ were eorrectedcorrected. ${ }^{43,44}$

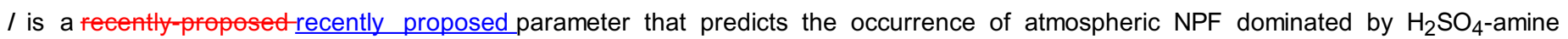
nucleation in the presence of a high aerosol toadingloading. ${ }^{24}$ - It is defined as

$I=\frac{\beta^{3}\left[\mathrm{~A}_{1, \text { tot }}\right]^{4}}{\mathrm{CS}^{2}} \eta^{4}$

where $\beta \underline{\beta}$ is the collision coefficient between two $\left(\mathrm{H}_{2} \mathrm{SO}_{4}\right)_{1}$ (amine $)_{1}$ clusters, $\left.\mathrm{cm}^{3}-\underline{S}-1\right] ; A_{1}$,tot refers to the total concentration of measured $\mathrm{H}_{2} \mathrm{SO}_{4}$ monomer, $\mathrm{cm}^{3}$; and $\mathrm{CS}$ is the condensation sink (note that the enhancement factor of coagulation between clusters due to van der Waals forces was taken into account, and this factor was estimated to be 2.3 and 1.3 for $\beta \underline{\beta}$ and CS, respectively), s $-1 \underline{1}$; $\cap n$ is the ratio of the $\left(\mathrm{H}_{2} \mathrm{SO}_{4}\right)_{1}$ (amine) $)_{1}$ cluster concentration to the total $\mathrm{H}_{2} \mathrm{SO}_{4}$ monomer concentration given by

$\eta=\frac{\left[\mathrm{A}_{1} \mathrm{~B}_{1}\right]}{\left[\mathrm{A}_{1}\right]+\left[\mathrm{A}_{1} \mathrm{~B}_{1}\right]} \approx \frac{\beta[\mathrm{B}]}{\gamma(T)+\mathrm{CS}+\beta[\mathrm{B}]} \quad 3$

here, $\left[\mathrm{A}_{1} \mathrm{~B}_{1}\right]$ represents $\left(\mathrm{H}_{2} \mathrm{SO}_{4}\right)_{1}$ (amine $)_{1}$ concentration, $\mathrm{cm}^{3} ;\left[\mathrm{A}_{1}\right]$ is the concentration of $\mathrm{H}_{2} \mathrm{SO}_{4}$ molecules, $\mathrm{cm}^{3}$; $[\mathrm{B}]$ indicates the amine concentration, $\mathrm{cm}^{3} ; T$ is the temperature, $\mathrm{K} ; \forall$ and $\gamma$ represents the evaporation rate of $\left(\mathrm{H}_{2} \mathrm{SO}_{4}\right)_{1}(\mathrm{amine})_{1}$ as a function of $T, \mathrm{~s}-11$. Since $\left[A_{1}\right]$ and $\left[A_{1} B_{1}\right]$ cannot be directly measured using the current instruments, $\eta \underline{n}$ was calculated using the rightmost formula in eq 3 . Since the 
amine concentration was missing in winter and spring of 2018, a constant amine concentration, 2.7 ppt, which is the median of the measured amine concentration, was used when estimating $\mathrm{n} n$ (see details in the SI). As a result, the analysis based on the indicator /mainly reflects the influence of the $\mathrm{H}_{2} \mathrm{SO}_{4}$ concentration, $\mathrm{CS}$, and temperature. More details on eqseqs $2 \underset{z}{z}$ and $3 \underline{3}$ are explained in the $\mathrm{SI}$ and by Cai et al. ${ }^{24}$

\section{3-.. Results and diseussionDiscussion}

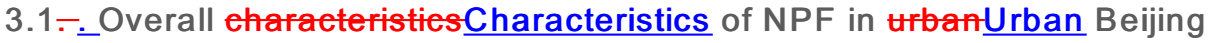

During our measurement periods, NPF event days and undefined days covered $37 \% 37$ and $6 \%$ of days, respectively. The daily maximum formation rate of $1.5 \mathrm{~nm}$ particles, $J_{1.5}$, during NPF periods ranged from 6 to $2200 \mathrm{~cm}-\underline{3} \cdot \mathbf{s}-1 \underline{1}$ with a median value of $79 \mathrm{~cm}$ (Figure 1). The values of $\mathrm{GR}_{4-31-3}, \mathrm{GR}_{3-7} \underline{3-7}, \mathrm{GR}_{7-15} \underline{-1-15_{1}}$ and $\mathrm{GR}_{45-2515-25}$ were in the ranges $0.2-2.4,0.6-5.2,1.1-8.0,0.2-2.4,0.6-5.2$.

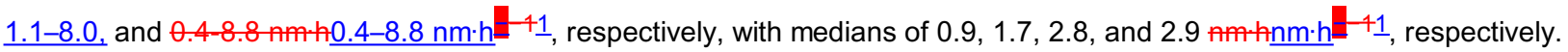

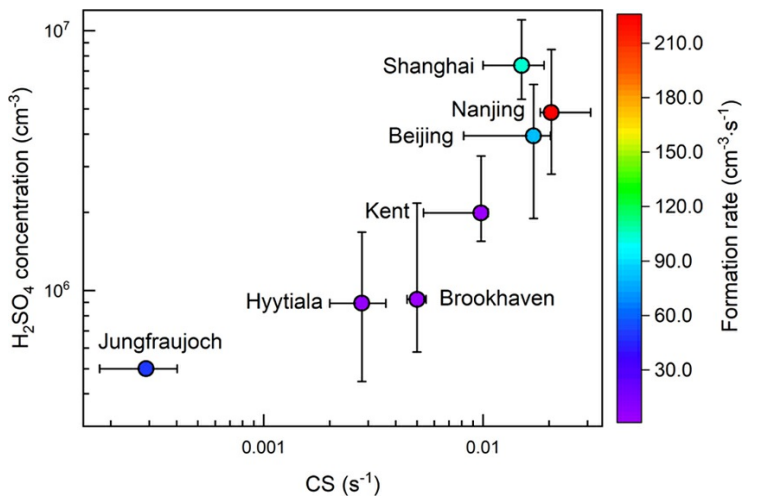

1-. The $\mathrm{H}_{2} \mathrm{SO}_{4}$ concentration and condensation sink in various atmospheric environments, including Beijing, Nanjing Nanjing. ${ }^{14}$, Shanghai Shanghai, ${ }^{15}$, Hyytiälä_Hyytiälä, ${ }^{45}$, Kent_Kent, ${ }^{62}$, Brookhaven Brookhaven, ${ }^{62}$ and Jungraujoch Jungraujoch. ${ }^{63,64}$ - Data points in this figure are the median values and colored by the median formation rate of sub- $2 \mathrm{~nm}$ particles. The error bars indicate the 25 th and 75 th percentiles, respectively. The $\mathrm{H}_{2} \mathrm{SO}_{4}$ concentration and CS in Beijing, Nanjing, ShanghaiShanghai, and Hyytiälä̈Hyytiälä are from long-term measurements $\left(\geq 7\right.$ ( $\geq 7$ months). The $\mathrm{H}_{2} \mathrm{SO}_{4}$ concentration in Kent, BrookhavenBrookhaven, and Jungfraujoch is from short-term measurements ( $<3$ months). CS in Jungfraujoch is from a long-term measurement. CS in Kent and Brookhaven is from short-term measurements.

In urban Beijing, we observed new particle formation events characterized with a high $J_{1.5}$, high CS, and high $\mathrm{H}_{2} \mathrm{SO}_{4}$ concentration (Figure 1). The maximum value of $J_{1.5}$ measured during this study exceeded $1000 \mathrm{~cm}-{ }_{3}^{3}-\underline{S}-1+1$, coinciding with the high $\mathrm{H}_{2} \mathrm{SO}_{4}$ concentration $\left(\sim 2.5 \times\left(\sim 2.5 \times 10^{7} \mathrm{~cm}-\stackrel{3}{-3}\right)\right.$ observed during that NPF event (Feb.(February 4, 2018). The aerosol loading, characterized by CS, was high in urban Beijing eomparedcompared to to-those observed in relatively clean environments (Figure 1). The median value of CS during the NPF periods in urban Beijing was $-0.019 \underline{0.019} \mathrm{~s}^{-1}-1$, while it was $-0.0025 \sim 0.0025 \mathrm{~s}^{-1}-1$ in the Finnish boreal forest of HyytiäläHyytiälä. ${ }^{45}$ The high CS in urban Beijing implies that the scavenging loss rates of gaseous precursors, elustersclusters, and newly formed particles are high. The median daily maximum $\mathrm{H}_{2} \mathrm{SO}_{4}$ concentration the-during NPF periods in urban Beijing was $-4 \times \underline{4} \times 10^{6} \mathrm{~cm}-\underline{-3}$, a factor of $-4 \sim 4$ higher than those in cleaner environments but close to those in other megacities (Figure 1).

Note that after properly correcting for the coagulation scavenging effect using eq 1 and with direct measurement of sub-3 nm particles, $J_{1.5}$ reported in this study is higher than that reported in a previous long-term study in urban BeijingBeijing. ${ }^{17}$ - Even with the same dataset of measured sub-3 $\mathrm{nm}$ particles, the formula used in previous studies underestimates the formation rate of $1.5 \mathrm{~nm}$ particles (Figure S3 in the $\mathrm{SI})$. This discrepancy is mainly attributed to the fact that underestimating or neglecting the coagulation scavenging effect of small particles will underestimate the formation rate in atmospheric environments with a-high aerosol toadingloading. ${ }^{11}$ - The high values of $J_{1.5}$ observed in this long-term measurement are consistent with the values recently reported in urban Beijing during a short-term field eampaigncampaign. ${ }^{11}$.

From a global perspective, the new particle formation rate in polluted environments appears to be higher than that in relatively clean areas. As shown in Figures 1 and 2, the formation rates of $-1.5 \sim 1.5 \mathrm{~nm}$ particles in Chinese megacities, such as Beijing, Shanghai, and Nanjing, 
are much higher than those in other relatively clean sites, such as the Finnish boreal forest of Hyytiälä.Hyytiälä. The inferred nucleation rates were reported to be very high as well in other polluted megacities, such as Mexico City and Delhi (although the formation rate of $-1.5 \sim 1.5 \mathrm{~nm}$ particles in these places werewas not directly measured)measured). ${ }^{12,46,47}$. In addition, relatively high formation rates of -1.5 1.5 nm particles were observed in Po Valley (Figure 2). Although Po Valley is labeled as a rural site, it is strongly influenced by anthropogenic emissions from the industrial areas and is surrounded by the mountainsmountains. ${ }^{48}-$ Its relatively high CS $(\sim 0.011(\sim 0.011$ $\mathrm{s}-1$ ) reflects the polluted characteristics of Po Valley.

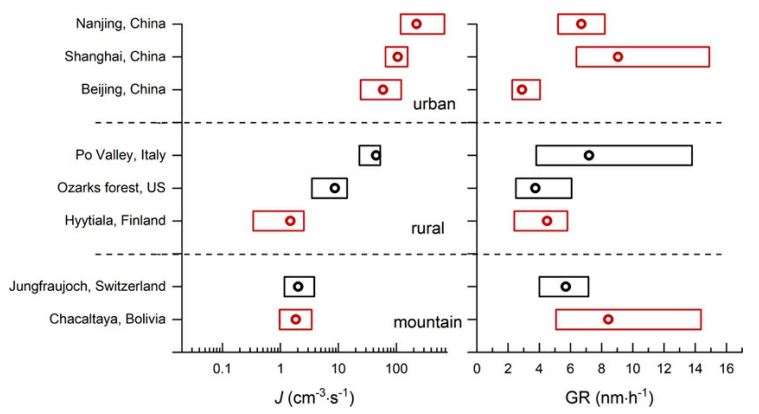

2-._Comparison of (a) the formation rate of sub-2 $\mathrm{nm}$ particles, $J$, and (b) the particle growth rate, GR $7-15 \underline{7-15}$, in various environments,

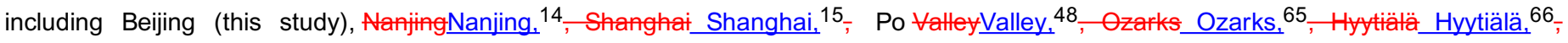
Jungfraujoch Jungfraujoch. ${ }^{63}$, and ChacaltayaChacaltaya. ${ }^{51}$. Urban, furatrural, and mountain environments are divided by dash lines. Data from long-term measurements $(\geq 7$ ( $\geq 7$ months) are shown by red color and the data from short-term field campaigns (<3 months) by black color. Circles represent median values. The left and right edges of bars are $25 \% \underline{25}$ and $75 \%$ percentiles, respectively, expectexcept for Po Valley that indieate $5 \%$ indicates 5 and $95 \%$ percentiles, respectively, and for HyytiäläHyytiälä that indicate one standard deviation. $J_{1.5}$ is used for Beijing. $J_{1.4}, J_{1.7}, J_{1.6_{1}}$ and $J_{1}$ are used for Nanjing, Shanghai, Po Valley, and Ozark forest, respectively. $J_{2}$ is used for Hyälä, Hyytiälä, Jungfraujoch, and Chacaltaya. GR $7-15 \underline{7-15}, G_{3-20,3-20}$ and $\mathrm{GR}_{5-25 \underline{5-25}}$ are used for Beijing, Nanjing, and Ozarks forest, respectively. GR $7-25 \underline{7-25}$ is used for Shanghai and Hyytiälä. Hyytiälä. GR $7-20 \underline{7-20}$ is used for Po Valley, Jungfraujoch, and Chacaltaya.

Despite the high formation rate of $-1.5 \sim 1.5 \mathrm{~nm}$ particles, the observed growth rate in urban Beijing was relatively lower. The median value

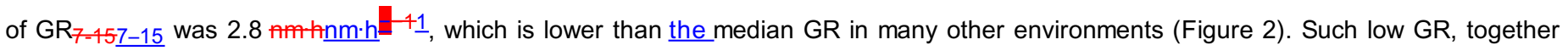
with high CS, in urban BeijingBeijing, may explain the observations that newly formed particles in urban Beijing sometimes cannot grow into very large sizessizes, although the formation rate is high (see anthe example in Figure S2). Note that uncertainties may be introduced when using different methods to estimate the observed GR. In addition, the observed GR is not equivalent to the condensational GR of an individual particle because the coagulation scavenging effect is not excluded when estimating the observed GR using the log-normal distribution function methodmethod. ${ }^{42,49}$

\section{2-. Seasonal variations $\underline{V}$ ariations of NPF frequeney Frequency and formation rateFormation Rate in} urbanurban Beijing

The occurrence of NPF in urban Beijing had a strong seasonal variation (Figure 3). In winter, spring, summer, and autumn of 2018, the NPF frequencies were $51.4 \%, 25.4 \%, 16.7 \% 51.4,25.4,16.7$ and $30.2 \%$, respectively. This is generally consistent with the previous observations in urban Beijing in the years of $2004^{16}$ and $20082008 .{ }^{50}$. For these years, the NPF frequency was also the highest in winterwinter. whereas it was the lowest in summer. The lowest NPF frequency in summer was also observed in Shanghaishanghai. ${ }^{15_{-}}$In Chacaltaya, however, the NPF frequency was found to be the highest in summersummer, whereas the lowest in winterwinter. ${ }^{51}$ - Similarly, in Hyytiälä, event was often found to be the lowest in 


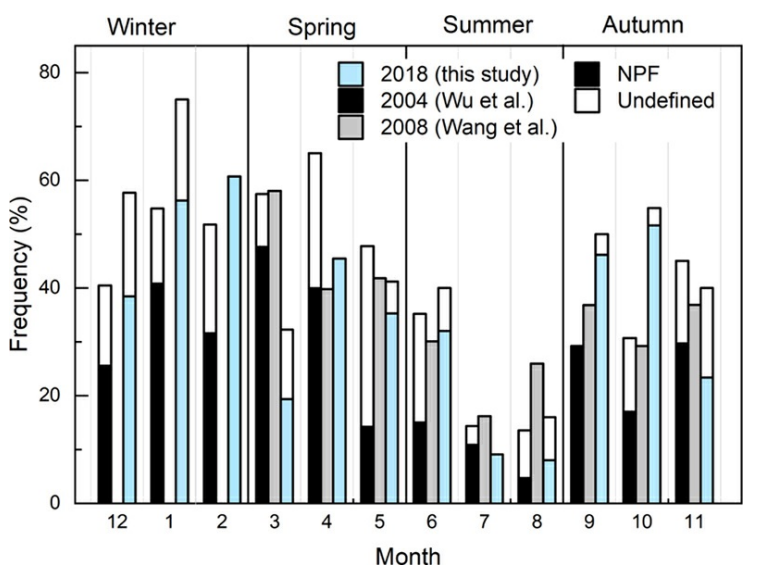

3-. FThe frequeney requency of NPF days and undefined days during each month in urban Beijing for the years $\theta=2018$ (this study), $20082008,{ }^{17}$; and $20042004,{ }^{16}$, respectively. Black, greygray, and blue colors indicate the frequencies of NPF days for the years $\theta$ f 2004 , 20082008 , and 2018, respectively. White color indicates the frequencies of undefined days. Note that the year ef 2004 is from March 2004 to February 2005 as reported by Wu et al. ${ }^{16}$

Similar to the observed variation of the NPF frequency in urban Beijing, the formation rate of $1.5 \mathrm{~nm}$ particles was much higher in winter than that in summer (Figure 4a). The seasonal cycle of formation rates is consistent with that observed previously in BeijingBeijing. ${ }^{16,17}$, although $J_{3}$ rather than $J_{1.5}$ was reported in those studies. The formation rate of $1.5 \mathrm{~nm}$ particles was also found to be the lowest in summer in ShanghaiShanghai. ${ }^{15}$ - In Hyytiälä, Hyytiälä, however, $J_{1.5}$ was estimated to be slightly higher in summer than in other seasons (although $J_{1.5}$ was estimated from a parametrization assuming heteromolecular nucleation between $\mathrm{H}_{2} \mathrm{SO}_{4}$ and oxidized erganies)organics). ${ }^{53}$

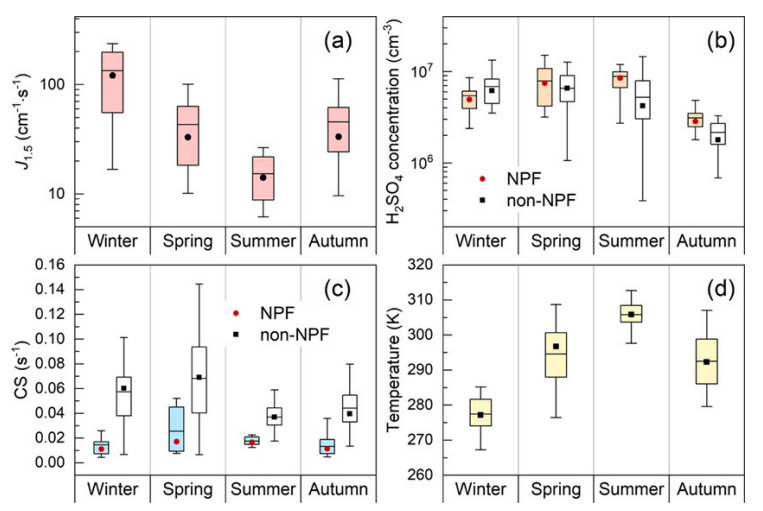

4-. Seasonal variations of (a) the formation rate of $1.5 \mathrm{~nm}$ particles $\left(J_{1.5}\right)$, (b) the $\mathrm{H}_{2} \mathrm{SO}_{4}$ concentration during NPF periods and non-NPF periods, (c) the condensation sink (CS) during NPF periods and non-NPF periodsperiods, and (d) ambient temperature. Colored-The colored and white box in (b) and (c) represent values during NPF periods and non-NPF periods, respectively. The bottom and top edges of the box indicate the 25th and 75th percentiles, respectively. The black line inside the box represents mean values. The circles and triangles indicate median values. CS values are the average during the NPF period on NPF days or 9:00-16:009:00-16:00 on non-NPF days. Daily maximum values of $J_{1.5}, \mathrm{H}_{2} \mathrm{SO}_{4}$ concentration (both on NPF days and non-NPF days), and temperature are used in (a), (b), and (d), respectively.

The seasonal variationvariations of the $\mathrm{H}_{2} \mathrm{SO}_{4}$ concentration and CS in urban Beijing are very different from those of the NPF frequency and $J_{1.5}$. The $\mathrm{H}_{2} \mathrm{SO}_{4}$ concentration showed no obvious difference during NPF periods and non-NPF periods (Figure 4b). Instead, the daily maximum $\mathrm{H}_{2} \mathrm{SO}_{4}$ concentration was slightly higher in summer than that in winter. The seasonal variation of the $\mathrm{H}_{2} \mathrm{SO}_{4}$ concentration is different from those observed in Shanghai and HyytiäläHyytiälä, where $\mathrm{H}_{2} \mathrm{SO}_{4}$ concentration was high in winter ${ }^{15}$ and springspring ${ }^{53}$ respectively. In addition, CS showed no remarkable seasonal variation during the NPF periods in urban Beijing (Figure 4c). This is similar to observations made in ShanghaiShanghai. ${ }^{15}$ - The median value of CS during the NPF periods in urban Beijing was $-0.019 \sim 0.019 \mathrm{~s}-11$, approximately 3 times lower than the median CS value during non-NPF days $(-0.057(\sim 0.057 \mathrm{~s}-11)$, further confirming that high pre-existing aerosols are able to suppress the occurrence of APFNPF. ${ }^{11}$.

Interestingly, the ambient temperature had an opposite seasonal cycle to that of the NPF frequency and $J_{1.5}$ in urban Beijing. Similar to other places, the ambient temperature in urban Beijing was the highest in summer and the-lowest in winter (Figure 4d). 
To explain the observed seasonal variation of $J_{1.5}$, we investigated the seasonal variation of the indicator $l$. The seasonal variation of the

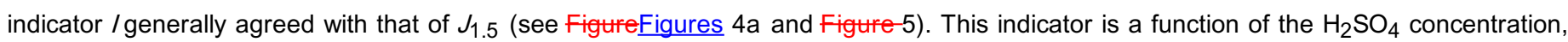
CS, and ambient temperature. Comparing / values estimated using both the measured temperatures and a constant temperature (275 K) during NPF periods, we found that the seasonal variation of the indicator / was mainly attributed to the seasonal variation of the ambient temperature (Figure 5).

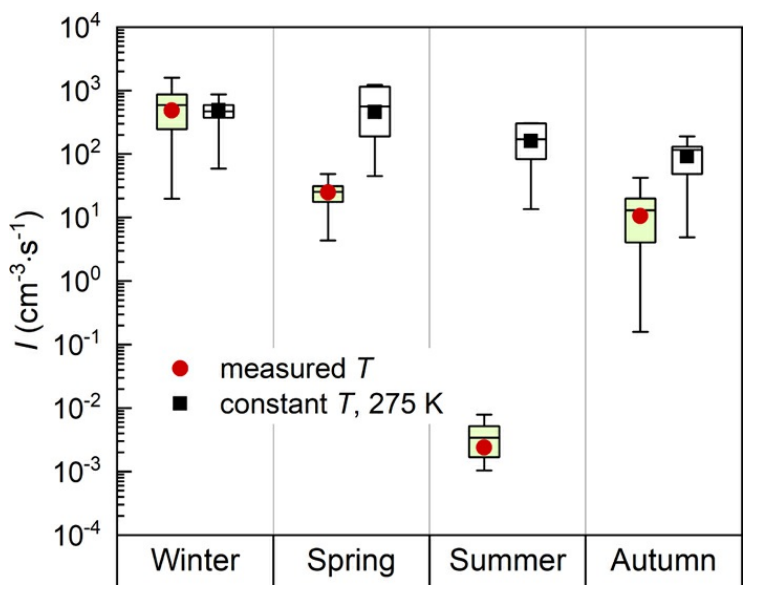

5-. Seasonal variations of the indicator, $l$, estimated at a constant ambient temperature of $275 \mathrm{~K}$ and the measured ambient temperature during NPF periods, respectively. The bottom and top edges of the box indicate the 25th and 75th percentiles, respectively. The black line inside the box represents the mean values. The dot and square markers indicate median values. Daily maximum values for /are used in this figure.

Based on the behavior of $l$, it seems likely that the seasonal variation of $J_{1.5}$ in urban Beijing was mainly driven by the seasonal variation of ambient temperature. $\mathrm{H}_{2} \mathrm{SO}_{4}$-amine nucleation governs new particle formation in urban Beijing Beijing. ${ }^{24,40}$. The -The evaporation rate of $\left(\mathrm{H}_{2} \mathrm{SO}_{4}\right)_{1}$ (amine) $)_{1}$ clusters is a function of temperature (see Equationegs S3 and Equation-S4 in the SI). In summer, the evaporation rate was the highest, whereas the ratio $(\mathrm{n})(\mathrm{n})$ of the $\left(\mathrm{H}_{2} \mathrm{SO}_{4}\right)_{1}$ (amine $)_{1}$ cluster concentration to the total $\mathrm{H}_{2} \mathrm{SO}_{4}$ monomer concentration was the lowest (Figure $\mathrm{S} 4$ in the $\mathrm{SI}$ ). The low values of $\mathrm{nn}$ indicate that although the $\mathrm{H}_{2} \mathrm{SO}_{4}$ monomer concentration was high and CS was low in summer, it was still difficult for zan NPF event to occur due to a high evaporation rate of $\mathrm{H}_{2} \mathrm{SO}_{4}$-amine clusters. Previous chamber studies reported that $\mathrm{H}_{2} \mathrm{SO}_{4}$-amine nucleation is rather insensitive to the temperature at high amine eoncentrationsconcentrations. ${ }^{55_{-}}$However, the above evidencesevidence and analysis in urban Beijing indicates that the temperature should be taken into account,account because amine concentrations in urban Beijing are not high enough to make the formation rate of $1.5 \mathrm{~nm}$ particles insensitive to cluster evaporationevaporation. ${ }^{24}$

Note that when estimating the values of / in Figure 5, a constant amine concentration of 2.7 ppt was tsectused. ${ }^{24,40}$. When including the variations of amine concentration during the five-menth meausement, 5 -month measurement, ambient temperature still remained the main factor governing the seasonal variation of /values (see Figure S5 and related discussions in the SI). Nevertheless, long-term measurements of amines and other gaseous precursors are needed to further evaluate their contributions to the observed seasonal variations. Different from urban Beijing, the seasonal variation of the new particle formation rate in HyytiäläHyytiälä was reported to be strongly related to the concentration variations of $\mathrm{H}_{2} \mathrm{SO}_{4}$ and erganies compoundsorganic compounds. ${ }^{45}$. Evidenees Evidence from previous chamber studies and ambient measurements indicate that the nucleation process of $\mathrm{H}_{2} \mathrm{SO}_{4}$ molecules and oxidized organics are able to explain new particle formation in HyytiäläHyytiälä. ${ }^{56-58}$. The differences in nucleation mechanisms and the governing factors possibly lead to the observed different seasonal variations of NPF frequency and formation rate in different places.

\section{3-. Seasonal variations Variations of growth rateGrowth Rate in urbanurban Beijing}

Despite the clear seasonal variations in the NPF frequency and $J_{1.5}$ in urban Beijing, the observed GRs in various size ranges were generally within the same range for all of the four seasons (Figure 6). Previous studies also reported no significant seasonal variations in the growth rate of nucleation mode particlesparticles. ${ }^{16,17}$ - Here, we further showed that the growth rates of sub-3 $\mathrm{nm}$ particles in four seasons are in the a similar range, though with some variations. Similar to Beijing, the observed GR in Shanghai showed no clear seasonal variation, although the observed GR in Shanghai was higher than that in BeijingBeijing. ${ }^{15_{-}}$In Hyytiälä, Hyytiälä, the observed GR was often 
found to be the highest in summer, which is most likely related to the high abundance of biogenic volatile organic compounds at that time of the yearyear. ${ }^{45_{-}}$It is interesting to point out that the GR increases with an increasing particle size in urban Beijing, as reported previouslypreviously. ${ }^{40}$. A similar feature has been observed in a number of other sites as well, such as HyytiäläHyytiälä, ${ }^{41}$, Shanghai Shanghai, ${ }^{15}$, Po $\forall a l l e y$ Valley, ${ }^{48}$ and ChacaltayaChacaltaya. ${ }^{51}$. This has been suggested to be caused by a reduced Kelvin effect with an increasing particle sizesize. ${ }^{59}$

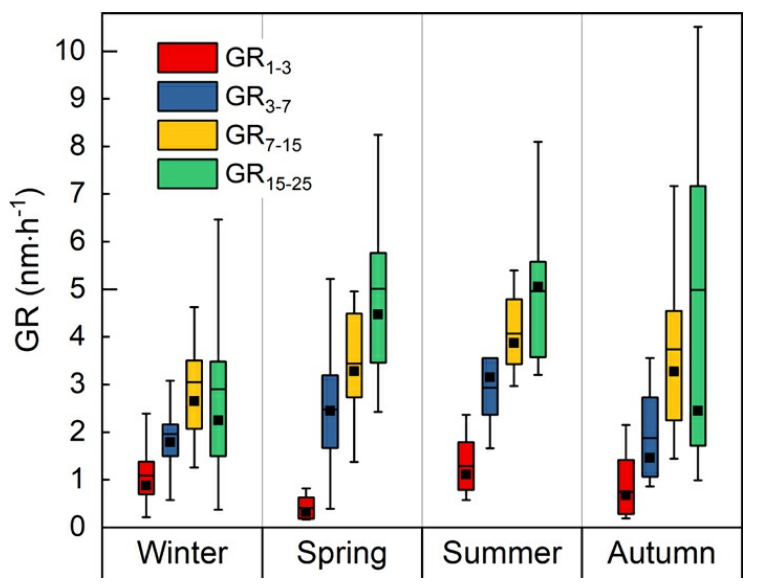

6-. Seasonal variations of the growth rates in various size ranges on NPF days. The bottom and top edges of the box indicate the 25 th and 75th percentiles, respectively. The black line inside the box represents the mean values. The square markers indicate median values.

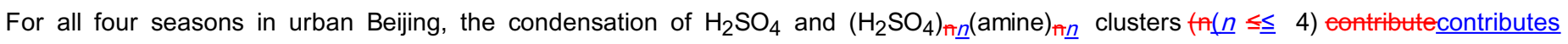
significantly to the observed GR of sub-3 nm particles with their minor seasonal variations (Figure 7a). Assuming kinetic condensation, the growth rate due to the condensation of $\mathrm{H}_{2} \mathrm{SO}_{4}$ and its clusters $\left(\mathrm{GR}_{\text {calculated }}\right.$ ) can be calculated as a function of particle size ${ }^{60}$ (see the $\mathrm{SI}$ for details). As shown in Figure $7 \mathrm{a}$, the ratios of the calculated $\mathrm{GR}_{1-3}$ over the observed $\mathrm{GR}_{1-31-3}$ in all four seasons are close to 1 , indicating that the condensation of $\mathrm{H}_{2} \mathrm{SO}_{4}$ and its clusters eontributecontributes significantly to the growth of particles in the sub-3 nm size range. These ratios are generally in the same range, though with some seasonal variations possibly related to the abundance of $\mathrm{H}_{2} \mathrm{SO}_{4}$ and its clusters in different seasons (Figure $4 \mathrm{~b}$ ) and the variations in the observed $\mathrm{GR}_{4-31-3}$ (Figure 6). The yearly data in urban Beijing also supports that the condensation of $\mathrm{H}_{2} \mathrm{SO}_{4}$ and stabilized $\mathrm{H}_{2} \mathrm{SO}_{4}$-base clusters eontributecontributes significantly to the measured $\mathrm{GR}$ for sub-3 $\mathrm{nm}$ particles (Figure S6a in the SI). This was observed in Shanghai ${ }^{15}$ and in some controlled chamber conditions ${ }^{28}$ as well. Note that there are uncertainties in both the calculated GR and the observed GR, especially in the sub-3 nm size range. For instance, the observed GR in the sub-3 nm size range is influenced by the estimation method, and thusmethod and, thus, has an impact on the ratios of the calculated $\mathrm{GR}_{1-31-3}$ over the observed $\mathrm{GR}_{1-3 \underline{1-3}}$. As shown in Figure $\mathrm{S} 6 \mathrm{~b}$, a recently corrected appearance time method ${ }^{21} \mathrm{gave}$ higher values of the observed $\mathrm{GR}_{1-3} \underline{1-3}$ than the log-normal distribution function method, and thusmethod and, thus, lower ratios. Nevertheless, results from both methods support that the condensation of $\mathrm{H}_{2} \mathrm{SO}_{4}$ and its clusters eontributecontributes significantly to the growth of particles in the sub-3 nm size range.
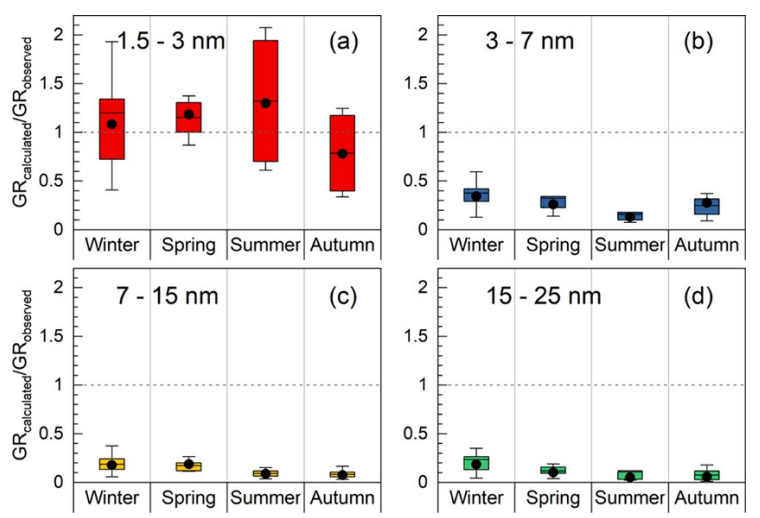

7-. RThe ratio-atio of the calculated growth rate $\left(G_{\text {calculated }}\right)$ over the observed growth rate ( $\left(R_{\text {observed }}\right)$ in four seasons for various size

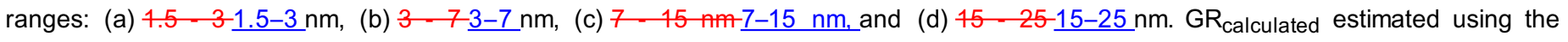
condensation of $\mathrm{H}_{2} \mathrm{SO}_{4}$ and $\left(\mathrm{H}_{2} \mathrm{SO}_{4}\right)_{\pi \underline{n}}$ (amine) $)_{n \underline{n}}$ clusters $(n \underline{n} \underline{n} \leq \underline{4})$. The geometric mean value of $\mathrm{GR}_{\text {calculated }}$ in each size rage was used

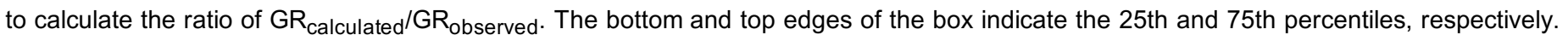


The black line inside the box represents the mean values. The dot markers indicate median values.

For all of the four seasons in urban Beijing, however, the condensation of $\mathrm{H}_{2} \mathrm{SO}_{4}$ and its clusters is less important for the growth rate of particles larger than $3 \mathrm{~nm}$ (Figure $7 b-d), \underline{b-d}$ ), indicating the contributions of other species. In all seasons, the ratios of the calculated GR over the observed GR decreased as the particle size increased and are less than $25 \%$ for particles greater than $7 \mathrm{~nm}$. Similar to the observed GR, there is no strong seasonal variations in these ratios. Other species, such as extremely low and low volatile compounds,

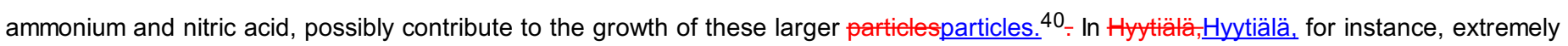
low-volatility organic compounds were found to be sufficient to explain the observed GR in larger size fangesranges. ${ }^{27}$ - As indicated by Figures 6 and 7, their total contribution to the observed GR in urban Beijing has no significant seasonal variaiton-variation. To further investigate these gas species and their contributions, revealing that the chemical compositions of nanoparticles as they grow will be very helpful. Instruments such as the thermal desorption chemical ionization mass spectrometer (TDCIMS) ${ }^{61}$ will be needed to directly measure the compositions of nanoparticles in this size range. It is also crucial to further understand the formation and physicochemical properties of low-volatility gas precursors (in addition to $\mathrm{H}_{2} \mathrm{SO}_{4}$ and its clusters).

With the measurement of aerosol size distributions down to $-1 \sim 1 \mathrm{~nm}$, sulfuric acid, amines, and their clusters, we addressed the seasonal characteristics of new particle formation and its governing factors in the urban environment of Beijing. In contrast to the negligible influence of temperature on the $\mathrm{H}_{2} \mathrm{SO}_{4}$-amine nucleation in chamber studies at high amine eoncentrationsconcentrations, ${ }^{55_{\text {, a strong temperature }}}$ effect was observed under atmospheric conditions in urban Beijing. Low atmospheric Low-atmospheric temperature favors the stability of $\mathrm{H}_{2} \mathrm{SO}_{4}$-amine elusters, and thusclusters and, thus, the formation of new particles. Accordingly, the formation of $1.5 \mathrm{~nm}$ particles in urban Beijing showed a clear seasonal variation with maxima in winter and minima in summer. This may have implications on new particle formation within the global range since both seasonal variations and vertical variations in atmospheric temperature occur throughout the troposphere. Considering this effect in global models may lead to better estimate estimation of the budget of atmospheric aerosols and their impactsimpacts. ${ }^{5}$ - In contrast, the growth rates of both sub 3 -sub-3 $\mathrm{nm}$ particles and larger particles showed little seasonal variation in urban Beijing. While the condensation of $\mathrm{H}_{2} \mathrm{SO}_{4}$ and $\mathrm{H}_{2} \mathrm{SO}_{4}$-amine clusters eontributecontributes significantly to the growth of sub-3 particles in urban Beijing, its contribution to the observed growth rates decreases fapdilyrapidly as the particle size increases. This emphasizes the need to search for other condensing species that account for the growth of larger particles. In addition, the strong coagulation effect and the rich mixture of various gas precursors in the urban environment may have profound influences on particle grothgrowth, which need to be further addressed.

\section{Supporting information}

The supporting information is available free of charge on the ACS Publication website.

It includes the classification of NPF, non-NPFnon-NPF, and undefined days (Figure S1); Anan example for evaluating the observed growth rate (Figure S2); The-calculation of the condensation sink (Eq.(eqs S1 and Eq.S2); The-comparison of the formation rate of 1.5 $\mathrm{nm}$ particles estimated using two formulae (Figure S3); Đetailsdetails on the indicator $l$, The-calculation of the evaporation rate (Eq-(eqs S3 and Eq.S4); The evaporation rate and $\eta \underline{n}$ as a function of temperature in four seasons (Figure S4); Moremore information on the measurement of amines and the influence of seasonal variation of amine concentration (Figure S5); The-calculation of the growth rate due to the condensation of $\mathrm{H}_{2} \mathrm{SO}_{4}$ and its clusters (Eq. S5, Eq. S6, Eq. S7 and Eq. S8); The (eqs S5-S8); influence of seasonal variations of amine concentration (Fig.(Figure S5); The-ratio of the calculated growth rate $\left(\mathrm{GR}_{\text {calculated }}\right)$ over the observed growth rate $\left(\mathrm{GR}_{\mathrm{observed}}\right)$ in various size fangeranges estimated using two different methods during these measurement periods (Fig.(Figure S6) (PDF)

\section{Acknowledgments}

Financial support from the National Key R\&ER\&D Program of Ghina(2017YFC0209503), China (2017YFC0209503), the National Science Foundation of China (21876094 91643201)and 91643201), and Samsung $\mathrm{PM}_{2.5}$ SRP are acknowledged. This project has received funding from the ERC advaneed grant No.Advanced Grant no. 742206, the European Union'sunion's Horizon 2020 research, and from the 
Academy of Finland (Center of Excellence project no. 27204 and project no. 316114). We thank Zhengning Xu and Yuliang Liu for their help in sulfuric acid data in Nanjing.

\section{References}

1 Kulmala- M.- Vehkamäkivehkamäki- H.- PetäjäPetäjä- T.- Dal Maso- M.- Lauri- A.- Kerminen- V. M.- Birmili- W.- McMurry- P. H.- Formation and growth rates of ultrafine atmospheric particles: a review of observations _ Journal. of $\mathrm{J}$. Aerosol ScieneeSci.- 2004- 35- 2- 143- 176- 10.1016/j.jaerosci.2003.10.003.

2Zhang- R.- Khalizov- A.- Wang- L.- Hu- M.- Xu- W.- Nucleation and growth of nanoparticles in the atmosphere- Chem RevChem. Rev.- 2012-112- 3- 1957- 2011- 10.1021/cr2001756.

3Makkonen- R.- Asmi- A.- Kerminen- V. M.- Boy- M.- Arneth- A.- Hari- P.- Kulmala- M.- Air pollution control and decreasing new particle formation lead to strong climate warming- AAtmospherie Chemistry and Physiestmos. Chem. Phys.- 2012-12- 3- 1515- 1524- 10.5194/acp12-1515-2012.

4Kerminen- V.-M.- Lihavainen- H.- Komppula- M.- Viisanen- Y.- Kulmala- M.- Direct observational evidence linking atmospheric aerosol formation and cloud droplet activation- GeophysiealReseareh LettersGeophys. Res. Lett.- 2005- 32- 14-- L14803- 10.1029/2005GL023130.

5Merikanto- J.- Spracklen- D. V.- Mann- G. W.- Pickering- S. J.- Carslaw- K. S.- Impact of nucleation on global CCN- AAtmospherie Chemistry and Physiestmos. Chem. Phys.- 2009- 9- 21- 8601- 8616- 10.5194/acp-9-8601-2009.

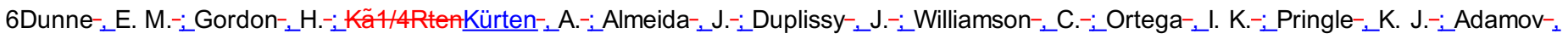

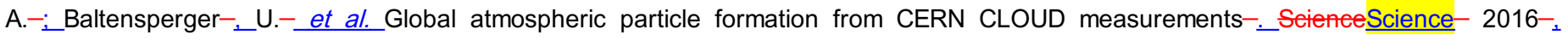
354-6316-1119-1124-.10.1126/science.aaf2649.

7Kerminen- V.-M.- Chen- X.- Vakkari- V.- PetäjäPetäjä- T.- Kulmala- M.- Bianchi- F.- Atmospheric new particle formation and growth: review of field observations- EEEnvironmental Research Lettersnviron. Res. Lett.- 2018- 13- 10- - 103003- 10.1088/1748-9326/aadf3c.

8Chu- B.- Kerminen- V.-M.- Bianchi- F.- Yan- C.- PetäjäPetäjä- T.- Kulmala- M.- Atmospheric new particle formation in China- AAtmospherie Chemistry and Physiestmos. Chem. Phys.- 2019-19-1- 115- 138- 10.5194/acp-19-115-2019.

9McMurry- P. H.- Friedlander- S. K.- New particle formation in the presence of an aerosol- AtmespherieAtmos. Environ. Environment 1979- 13- 12- 1635- 1651- 10.1016/0004-6981(79)90322-6.

10Kerminen- V.-M.- Pirjola- L.- Kulmala- M.- How significantly does coagulational scavenging limit atmospheric particle production?- $\underline{\text { JJurnat }}$ ef Geophysical Researeh: Atmospheres. Geophys. Res.: Atmos.- 2001- 106- D20- 24119- 24125- 10.1029/2001JD000322.

11Cai- R.- Yang- D.- Fu- Y.- Wang- X.- Li- X.- Ma- Y.- Hao- J.- Zheng- J.- Jiang- J.- Aerosol surface area concentration: a governing factor in new particle formation in Beijing- AAtmospherie Chemistry and Physiestmos. Chem. Phys.- 2017- 17- 20- 12327- 12340- 10.5194/acp-17$12327-2017$.

12lida- K.- Stolzenburg- M. R.- McMurry- P. H.- Smith- J. N.- Estimating nanoparticle growth rates from size-dependent charged fractions: Analysis of new particle formation events in Mexico City- JJournal of Geophysieal Research: Atmospheres. Geophys. Res.: Atmos.- 2008- 113- D5- - D05207- 10.1029/2007JD009260.

13Xiao- S.- Wang- M. Y.- Yao- L.- Kulmala- M.- Zhou- B.- Yang- X.- Chen- J. M.- Wang- D. F.- Fu- Q. Y.- Worsnop- D. R.- Wang- L.- Strong atmospheric new particle formation in winter in urban Shanghai, China- AAtmespheric Chemistry and Physiestmos. Chem. Phys.- 2015- 15- 4- 1769- 1781- 10.5194/acp-15-1769-2015.

14Yu- H.- Zhou- L.- Dai- L.- Shen- W.- Dai- W.- Zheng- J.- Ma- Y.- Chen- M.- Nucleation and growth of sub-3 nm particles in the polluted urban atmosphere of a megacity in China- AAtmespherie Chemistry and Physiestmos. Chem. Phys.- 2016- 16- 4- 2641- 2657- 10.5194/acp16-2641-2016. 
15Yao- L.- Garmash- O.- Bianchi- F.- Zheng- J.- Yan- C.- Kontkanen- J.- Junninen- H.- Mazon- S. B.- Ehn- M.- Paasonen- P.- Sipila- M.- Wang- M.- Wang- X.- Xiao- S.- Chen- H.- Lu- Y.- Zhang- B.- Wang- D.- Fu- Q.- Geng- F.- Li- L.- Wang- H .- Qiao- L.- Yang- X.- Chen- J.- Kerminen- V. M.- Petaja- T.- Worsnop- D. R.- Kulmala- M.- Wang- L.- Atmospheric new particle formation from sulfuric acid and amines in a Chinese megacity- ScienceScience- 2018- 361- 6399- 278- 281- 10.1126/science.aao4839.

16Wu- Z.- Hu- M.- Liu- S.- Wehner- B.- Bauer- S.- Ma BlingMassling- A.- Wiedensohler- A.- PetäjäPetäjä- T.- Dal Maso- M.- Kulmala- M.- New particle formation in Beijing, China: Statistical analysis of a 1-year data set- JournalJ. Geophys. Res. Of Geophysieat Research-2007-112- D9- - D09209- 10.1029/2006JD007406.

17Wang- Z. B.- Hu- M.- Sun- J. Y.- Wu- Z. J.- Yue- D. L.- Shen- X. J.- Zhang- Y. M.- Pei- X. Y.- Cheng- Y. F.- Wiedensohler- A.- Characteristics of regional new particle formation in urban and regional background environments in the North China Plain- AAtmespheric Chemistry and Physiestmos. Chem. Phys.- 2013- 13- 24- 12495- 12506- 10.5194/acp-13-12495-2013.

18Zheng- J.- Hu- M.- Zhang- R.- Yue- D.- Wang- Z.- Guo- S.- Li- X.- Bohn- B.- Shao- M.- He- L.- Huang- X.- Wiedensohler- A.- Zhu- T.- Measu rements of gaseous $\mathrm{H} 2 \mathrm{SO} 4$ by AP-ID-CIMS during CAREBeijing 2008 Campaign- AAtmospheric Chemistry and Physiestmos. Chem. Phys.- 2011- 11- 15- 7755- 7765- 10.5194/acp-11-7755-2011.

19Cai- R.- Jiang- J.- A new balance formula to estimate new particle formation rate: reevaluating the effect of coagulation scavenging- AAtmospheric Chemistry and Physiestmos. Chem. Phys.- 2017- 17- 20- 12659- 12675- 10.5194/acp-17-12659-2017.

20KürtenKürten- A.- Li- C.- Bianchi- F.- Curtius - J.- Dias- A.- Donahue- N. M.- Duplissy- J.- Flagan- R. C.- Hakala- J.- Jokinen- T.- Kirkby- J.- Kulmala- M.- Laaksonen- A.- Lehtipalo- K.- Makhmutov- V.- Onnela- A.- Rissanen- M. P.- Simon- M.- SipiläSipilä- M.- Stozhkov- Y.- Frösttröstl- J.- Ye- P.- McMurry- P. H.- New particle formation in the sulfuric aciddimethylamine-watefacid-dimethylamine-water system: reevaluation of CLOUD chamber measurements and comparison to an aerosol nucleation and growth model- AAtmospheric Chemistry and Physiestmos. Chem. Phys.- 2018- 18- 2- 845- 863- 10.5194/acp-18-845-2018.

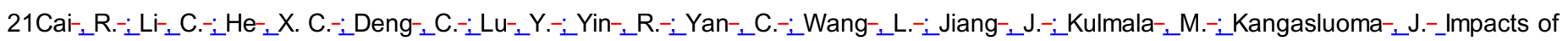
coagulation on the appearance time method for sub-3 nm particle growth rate evaluation and their corrections-. Atmos.Atmos. Chem. Phys. Discuss. Chem. Phys. Diseuss. 2020-_2020- _1-24. 10.5194/acp-2020-398.

22McMurry_ P. H.— Fink— M.— Sakurai— H.—_ Stolzenburg— M. R.— Mauldin- R. L.- Smith- J.- Eisele- F.- Moore- K.- Sjostedt- S.- Tanner- D.- Huey- L. G.- Nowak- J. B.- Edgerton- E.- Voisin- D.- A criterion for new particle formation in the sulfur-rich Atlanta atmosphere- +.J. Geophys. Res. Geophys. Res. 2005- 110- D22- 1- 10- 10.1029/2005JD005901.

23Kuang- C.- Riipinen- I.- Sihto- S. L.- Kulmala- M.- McCormick- A. V.- McMurry- P. H.- An improved criterion for new particle formation in

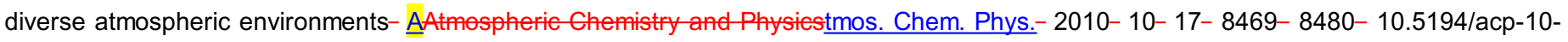
8469-2010.

24Cai, R.; Yan, C.; Yang, D.; Yin, R.; Lu, Y.; Deng, C.; Fu, Y.; Ruan, J.; Li, X.; Kontkanen, J.; Zhang, Q.; Kangasluoma, J.; Ma, Y.; Hao, J.; Worsnop, D. R.; Bianchi, F.; Paasonen, P.; Kerminen, V. M.; Liu, Y.; Wang, L.; Zheng, J.; Kulmala, M.; Jiang, J.; SulfurieSulfuric Acid-Amine Nucleation in the[AQ1] Urban Atmospheric Environment-acid-amine nucleation in the urban atmospheric environment., 2020- ${ }_{2}$ under review.(under review).

25Smith- J. N.- Moore- K. F.- Eisele- F. L.- Voisin- D.- Ghimire- A. K.- Sakurai- H.- McMurry- P. H.- Chemical composition of atmospheric nanoparticles during nucleation events in Atlanta- JournatJ. Geophys. Res. of Geophysieat Research-2005- 110- D22-- D22S03- 10.1029/2005JD005912.

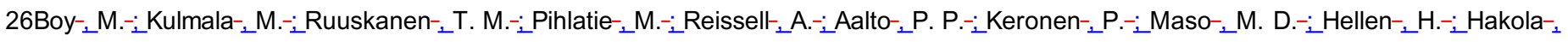
H.- et al. Sulphuric acid closure and contribution to nucleation mode particle growth-. AAtmospherie Chemistry and Physiestmos. Chem. Phys.- 2005- _5-4- 863- 878-. 10.5194/acp-5-863-2005.

27Ehn- M.- Thornton- J. A.- Kleist- E.- Sipila- M.- Junninen- H.- Pullinen- I.- Springer- M.- Rubach- F.- Tillmann- R.- Lee- B.- LopezHilfikerF. AndresS. AcirI. 
H.- Rissanen- M.- Jokinen- T.- Schobesberger- S.- Kangasluoma- J.- Kontkanen- J.- Nieminen- T.- Kurten- T.- Nielsen- L. B.- Jorgensen- S.- Kjaergaard- H. G.- Canagaratna- M.- Maso- M. D.- Berndt- T.- Petaja- T.- Wahner- A.- Kerminen- V. M.- Kulmala - M.- Worsnop - D. R.- Wildt- J.- Mentel- T. F.- A large source of low-volatility secondary organic aerosol- Nature- 2014- 506- 7489- 476- 9479- 10.1038/nature13032.

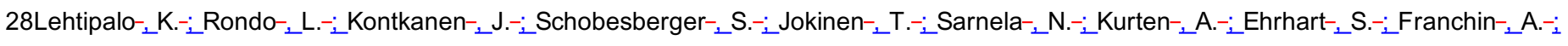

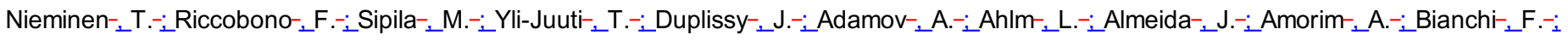

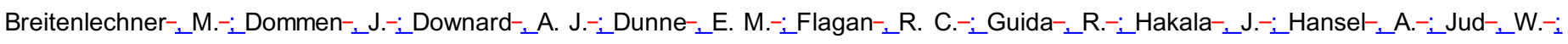

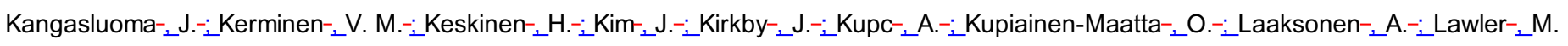

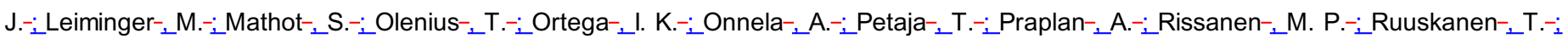

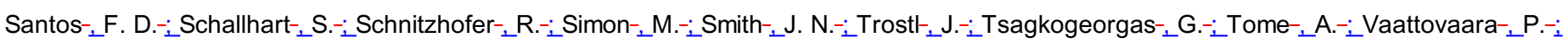

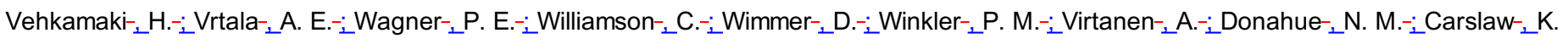

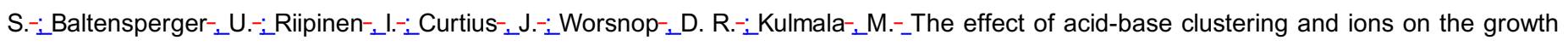
of atmospheric nano-particles-. Nat Commun Nat. Commun.- 2016-_, 7-_ 11594 . 11594. 10.1038/ncomms11594.

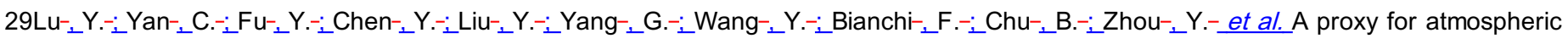
daytime gaseous sulfuric acid concentration in urban Beijing-. AAtmospheric Chemistry and Physiestmos. Chem. Phys.- 201919-3- 1971-1983-_10.5194/acp-19-1971-2019.

30Zhou- Y.- Dada- L.- Liu- Y.- Fu- Y.- Kangasluoma- J.- Chan- T.- Yan- C.- Chu- B.- Daellenbach- K. R.- Bianchi- F.- Kokkonen- T. V.- Liu- Y.- Kujansuu- J.- Kerminen- V. M.- PetäjäPetäjä- T.- Wang- L.- Jiang- J.- Kulmala- M.- Variation of size-segregated particle number concentrations in wintertime Beijing-Atmos.Atmos. Chem. Phys.-Chem. Phys. 2020- 20- 2- 1201- 1216- 10.5194/acp-20-1201-2020.

31Jiang- J.- Chen- M.- Kuang- C.- Attoui- M.- McMurry- P. H.- Electrical Mobility Spectrometer Using a Diethylene Glycol Condensation Particle Counter for Measurement of Aerosol Size Distributions Down to $1 \mathrm{~nm}$ - AAerosol Seience and Technologyerosol Sci. Technol.- 2011- 45- 4- 510- 521- 10.1080/02786826.2010.547538.

32Cai- R.- Chen- D.-R.- Hao- J.- Jiang- J.- A miniature cylindrical differential mobility analyzer for sub-3 nm particle sizing- Journal-of J. Aerosol SeienceSci.- 2017- 106- 111- 119- 10.1016/j.jaerosci.2017.01.004.

33Liu- J.- Jiang- J.- Zhang- Q.- Deng- J.- Hao- J.- A spectrometer for measuring particle size distributions in the range of $3 \mathrm{~nm}$ to 10 umum- FFrontiers of Envirenmental Seienee \& Engineeringront. Environ. Sci. Eng.- 2016- 10- 1- 63- 72- 10.1007/s11783-014-0754-x.

34Fu- Y.- Xue- M.- Cai- R.- Kangasluoma- J.- Jiang- J.- Theoretical and experimental analysis of the core sampling method: Reducing diffusional losses in aerosol sampling line-

AAerosol Seience and Technologyerosol Sci. Technol.- 2019- 53- 7- 793- 801- 10.1080/02786826.2019.1608354.

35Eisele- F.- Tanner- D.- Measurement of the gas phase concentration of H2SO4 and methane sulfonic acid and estimates of $\mathrm{H} 2 \mathrm{SO} 4$ production and loss in the atmosphere- JJournal of Geophysical Research: Atmospheres. Geophys. Res.: Atmos.- 1993- 98- D5- 9001- 9010- 10.1029/93JD00031.

36Bertram- T. H.- Kimmel- J. R.- Crisp- T. A.- Ryder- O. S.- Yatavelli- R. L. N.- Thornton- J. A.- Cubison- M. J.- Gonin- M.- Worsnop- D. R.- A field-deployable, chemical ionization time-of-flight mass spectrometer- AAtmospheric Measurement Techniquestmos. Meas. Tech.- 2011- 4- 7- 1471- 1479- 10.5194/amt-4-1471-2011.

37Jokinen- T.- SipiläSipilä- M.- Junninen- H.- Ehn- M.- Łönnt_önn- G.- Hakala- J.- PetäjäPetäjä- T.- Mauldin- R. L.- Kulmala- M.- Worsnop- D. R.- Atmospheric sulphuric acid and neutral cluster measurements using Cl-APi-TOF- AAtmospheric Chemistry and Physicstmos. Chem. Phys.- 2012- 12- 9- 4117- 4125- 10.5194/acp-12-4117-2012.

38KürtenKürten- A.- Rondo- L.- Ehrhart- S.- Curtius- J.- Calibration of a chemical ionization mass spectrometer for the measurement of gaseous sulfuric acid- The Journal of Physieal Chemistry J. Phys. Chem. A- 2012- 116- 24- 6375- 6386- 10.1021/jp212123n. 
39Heinritzi- M.- Simon- M.- Steiner- G.- Wagner- A. C.- Kürten Kürten- A.- Hansel- A.- Curtius- J.- Characterization of the mass dependent transmission efficiency of a CIMS- AtAtmospheric Measurement Techniques $\underline{\text { mos. Meas. Tech. }}$ Discuss. Diseussions 2015- 8- 11- 1449- 1460- 10.5194/amtd-8-11369-2015.

40Yan, C.; Dada, L.; Dallenbach, K.; Kontkanen, J.; Yin, R.; Lu, Y.; Yang, D.; Fu, Y.; Deng, C.; Baalbaki, R.; Schervish, M.; Cai, J.; Cai, R.; Bloss, M.; Chan, T.; Chen, T.; Chen, Q.; Hakala, S.; Chen, X.; Chen, Y.; Chu, B.; Du, W.; Ezhova, E.; Fan, X.; Feng, Z.; Foreback, B.; Garmash, O.; Guo, Y.; He, X.; Heikkinen, L.; Hussein, T.; Jarvi, L.; Jokinen, T.; Junninen, H.; Kangasluoma, J.; Kokkonen, T.; Kurppa, M.; Lehtinen, K.; Li, C.; Li, H.; Li, H.; Li, X.; Liu, Y.; Ma, Q.; Nie, W.; Paasonen, P.; Pileci, R.; Qiao, X.; Rantala, P.; Rusanen, A.; Sarnela, N.; Simonen, P.; Stolzenburg, D.; Tilgner, A.; Tuovinen, S.; Vakkari, V.; Wang, L.; Wang, S.; Wang, W.; Wang, Y.; Wang, Y.; Xue, M.; Yang, D.; Yang, G.; Yao, L.; Zhang, H.; Zhang, G.; Zhang, Y.; Zheng, F.; Zeng, X.; Zhou, Y.; Zhouhui, L.; Kujansuu, J.; Petaja, T.; Zhang, S.; Ma, Y.; Ge, M.; He, H.; Donahue, N. M.; Worsnop, D. R.; Kerminen, V. M.; Ding, A.; Zheng, J.; Wang, L.; Liu, Y.; Jiang, J.; Bianchi, F.; Kulmala, M.-; TheThe Birth of[AQ2] Haze-birth of haze.., 2020-, under review. (under review).

41Kulmala- M.- Petaja- T.- Nieminen- T.- Sipila- M.- Manninen- H. E.- Lehtipalo- K.- Dal Maso- M.- Aalto- P. P.- Junninen- H.- Paasonen- P.- Riipinen- I.- Lehtinen- K. E.- Laaksonen- A.- Kerminen- V. M.- Measurement of the nucleation of atmospheric aerosol particles- Nat ProtoeNat. Protoc.- 2012- 7- 9- 1651- 671667- 10.1038/nprot.2012.091.

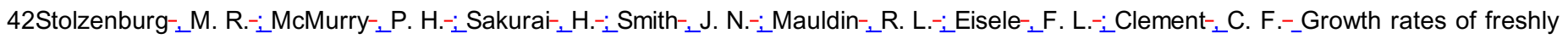
nucleated atmospheric particles in Atlanta-. JJournal of Geophysical Research. Geophys. Res.- 2005-_ 110-D22- S05-. S05. 10.1029/2005JD005935.

43Fuller- E. N.- Schettler- P. D.- Giddings- J. C.- New method for prediction of binary gas-phase diffusion coefficients- lindustrial \& Engineering Chemistrynd. Eng. Chem.- 1966- 58- 5- 18- 27-10.1021/ie50677a007.

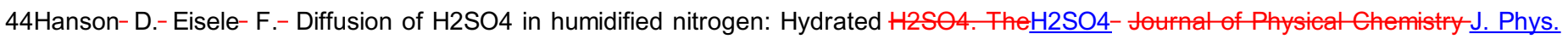
Chem. A- 2000-104- 8- 1715- 1719- 10.1021/jp993622j.

45Nieminen- T.- Asmi- A.- Maso- M. D.- Aalto- P. P.- Keronen- P.- Petaja- T.- Kulmala- M.- Kerminen- V. M.- Trends in atmospheric newparticle formation: 16 years of observations in a boreal-forest environment- Bor eal Environment ResearchEnviron. Res.- 2014- 19- 1- 191- 214

46Kulmala- M.- PetäjäPetäjä- T.- AönkkönenMönkkönen- P.- Koponen- I. K.- Dal Maso- M.- Aalto- P. P.- Lehtinen- K. E. J.- Kerminen- V. M.- On the growth of nucleation mode particles: source rates of condensable vapor in polluted and clean environments- Atmes.Atmos. Chem. Phys.-Chem. Phys. 2005- 5- 2- 409-416- 10.5194/acp-5-409-2005.

47Ä̈nkkënenMönkkönen- P.- Koponen- I. K.- Lehtinen- K. E. J.- HämeriHämeri- K.- Uma- R.- Kulmala- M.- Measurements in a highly polluted Asian mega city: observations of aerosol number size distribution, modal parameters and nucleation events- Atmos. Atmos. Chem. Phys. Ehem. Phys. 2005- 5- 1- 57- 66- 10.5194/acp-5-57-2005.

48Kontkanen- J.- JärvinenJärvinen- E.- Manninen- H. E.- Lehtipalo- K.- Kangasluoma- J.- Decesari- S.- Gobbi- G. P.- Laaksonen- A.- PetäjäPetäjä- T.- Kulmala- M.- High concentrations of sub-3nm clusters and frequent new particle formation observed in the Po Valley, Italy, during the PEGASOS 2012 campaign- AAtmospheric Chemistry and Physiestmos. Chem. Phys.- 2016- 16- 4- 1919- 1935- 10.5194/acp-16-1919-2016.

49teppäLeppä- J.- Anttila- T.- Kerminen- V. M.- Kulmala- M.- Lehtinen- K. E. J.- Atmospheric new particle formation: real and apparent growth of neutral and charged particles- AAtmespherie Chemistry and Physiestmos. Chem. Phys.- 2011- 11- 10- 4939- 4955- 10.5194/acp$11-4939-2011$.

50Wang- Z. B.- Hu- M.- Yue- D. L.- Zheng- J.- Zhang- R. Y.- Wiedensohler- A.- Wu- Z. J.- Nieminen- T.- Boy- M.- Evaluation on the role of sulfuric acid in the mechanisms of new particle formation for Beijing case- AAtmospheric Chemistry and Physiestmos. Chem. Phys.- 2011- 11- 24- 12663- 12671- 10.5194/acp-11-12663-2011.

51Rose- C.- Sellegri- K.- Velarde- F.- Moreno- I.- Ramonet- M.- Weinhold- K.- Krejci- R.- Ginot- P.- Andrade- M.- Wiedensohler- A.- Laj- P.- Fre 
quent nucleation events at the high altitude station of Chacaltaya (5240 m a.s.I.), Bolivia- AAtmospheric Environmenttmos. Environ.- 2015- 102- 18- 29- 10.1016/j.atmosenv.2014.11.015.

52Dal Maso- M.- Kulmala- M.- Riipinen- I.- Wagner- R.- Hussein- T.- Aalto- P. P.- Lehtinen- K. E.- Formation and growth of fresh atmospheric aerosols: eight years of aerosol size distribution data from SMEAR II, Hyytiala, Finland- Boreal Envirenment ResearehEnviron. Res.- 2005- 10- 5- 323

53Dada_ L.— Paasonen— P.— Nieminen— — B _-_ Buenrostro Mazon- S.- Kontkanen- J.- PeräkyläPeräkylä- O.- Lehtipalo- K.- Hussein- T.- PetäjäPetäjä- T.- Kerminen- V.M.- BäckBäck - J.- Kulmala- M.- Long-term analysis of clear-sky new particle formation events and nonevents in HyytiäläHyytiälä- AAtmospheric Chemistry and Physiestmos. Chem. Phys.- 2017- 17- 10- 6227- 6241- 10.5194/acp-17-6227-2017.

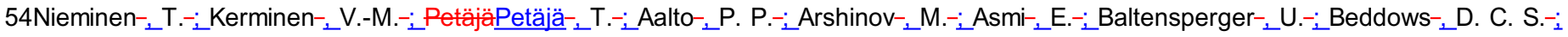

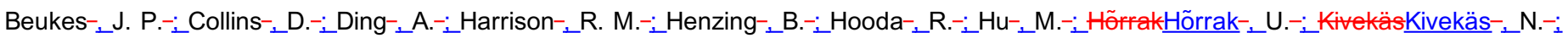

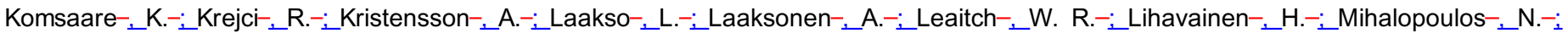
NémethNémeth-_Z.-;Nie-_,W.-; amp;O'Dowd-_asc.

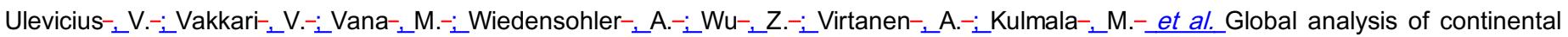
boundary layer new particle formation based on long-term measurements-. AAtmospheric Chemistry and Physiestmos. Chem. Phys.- 201818-19-14737-14756-.10.5194/acp-18-14737-2018.

55Almeida - J.- Schobesberger - S.- Kurten - A.- Ortega - I. K.- Kupiainen-Maatta- O.- Praplan- A P.- Adamov- A.- Amorim - A.- Bianchi- F.- Breitenlechner- M.- David- A.- Dommen- J.- Donahue- N

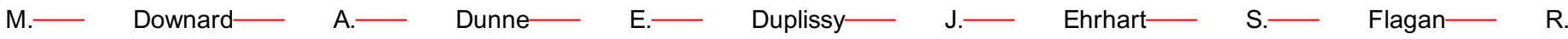
C.- Franchin- A.- Guida- R.- Hakala- J.- Hansel- A.- Heinritzi- M.- Henschel- H.- Jokinen- T.- Junninen- H.- Kajos- M.- Kangasluoma- J.- Keskin

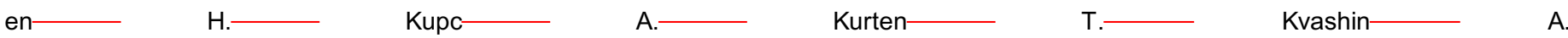
N.- Laaksonen- A.- Lehtipalo- K.- Leiminger- M.- Leppa- J.- Loukonen- V.- Makhmutov- V.- Mathot- S.- McGrath- M. J.- Nieminen- T.- Olenius- T.- Onnela- A.- Petaja- T.- Riccobono- F.- Riipinen- I.- Rissanen- M.- Rondo- L.- Ruuskanen- T.- Santos- F.

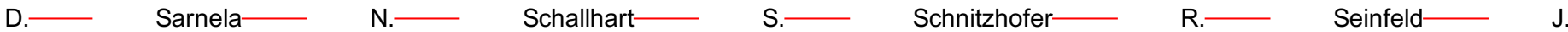
H.- Simon- M.- Sipila- M.- Stozhkov- Y.- Stratmann- F.- Tome- A.- Trostt- J.- Tsagkogeorgas- G.- Vaattovaara- P.- Viisanen- Y.- Virtanen- A.- Vr tala- A.- Wagner- P. E.- Weingartner- E.- Wex- H.- Williamson- C.- Wimmer- D.- Ye- P.- Yli-Juuti- T.- Carslaw- K. S.- Kulmala- M.- Curtius- J.- Baltensperger- U.- Worsnop- D. R.- Vehkamaki- H.- Kirkby- J.- Molecular understanding of sulphuric acid-amine particle nucleation in the atmosphere- Nature- 2013-502- 7471-359-63363-10.1038/nature12663.

56Schobesberger- S.- Junninen- H.- Bianchi- F.- Lonn- G.- Ehn- M.- Lehtipalo- K.- Dommen- J.- Ehrhart- S.- Ortega- I. K.- Franchin- A.- Nieminen- T.- Riccobono- F.- Hutterl- M.- Duplissy- J.- Almeida- J.- Amorim- A.- Breitenlechner- M.- Downard- A. J.- Dunne- $\quad$ E. $\quad$ M. $\quad$ FlaganC.- Kajos- M.- Keskinen- H.- Kirkby- J.- Kupc- A.- Kurten- A.- Kurten- T.- Laaksonen- A.- Mathot- S.- Onnela- A.- Praplan- A. $P$ Rondo

$\mathrm{L}$ Santos

D.- Schallhart- S.- Schnitzhofer- R.- Sipila- M.- Tome- A.- Tsagkogeorgas- G.- Vehkamaki- H.- Wimmer- D.- Baltensperger- U.- Carslaw- K S.- Curtius- J.- Hansel- A.- Petaja- T.- Kulmala- M.- Donahue- N. M.- Worsnop- D. R.- Molecular understanding of atmospheric particle formation from sulfuric acid and large oxidized organic molecules- Proc Natt Acad Sci $U$ S AProc. Natl. Acad. Sci. U.S.A.- 2013- 110- 43- 17223- 817228- 10.1073/pnas.1306973110.

57Metzger- A.- Verheggen- B.- Dommen- J.- Duplissy- J.- Prevot- A. S.- Weingartner- E.- Riipinen- I.- Kulmala- M.- Spracklen- D. V.- Carslaw-K. S.- Baltensperger- U.- Evidence for the role of organics in aerosol particle formation under atmospheric conditions- Proc Natt Acad SciU SAProc. Natl. Acad. Sci. U.S.A.- 2010- 107- 15- 6646- 516651- 10.1073/pnas.0911330107.

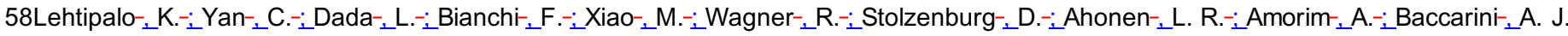
S. a. Multicomponent new particle formation from sulfuric acid, ammonia, and biogenic vapors. Multicomponent new particle formation from sulfurie acid, ammonia, and biogenic vapors Sci. Adv.- 2018-, 4-12--eaau5363. 10.1126/sciadv.aau5363. 
59Kuang- C.- Chen- M.- Zhao- J.- Smith- J.- McMurry- P. H.- Wang- J.- Size and time-resolved growth rate measurements of 1 to 5 nm freshly formed atmospheric nuclei- AAtmospheric Chemistry and Physiestmos. Chem. Phys.- 2012- 12- 7- 3573- 3589- 10.5194/acp-12-35732012.

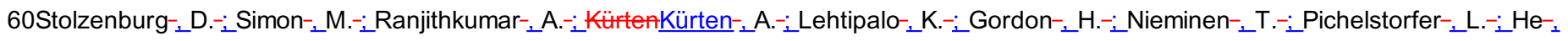

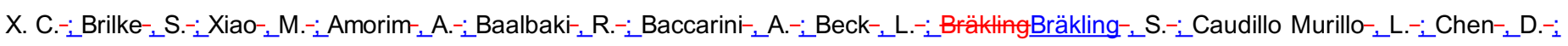

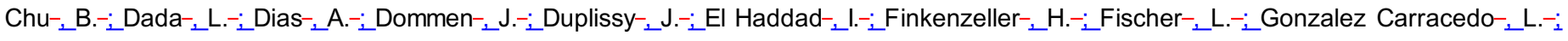

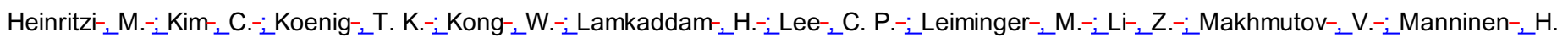

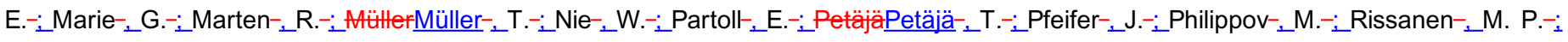

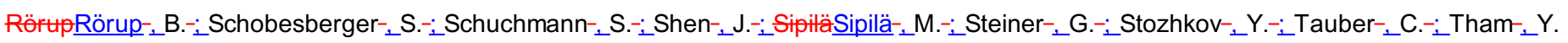

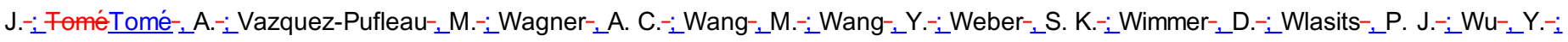

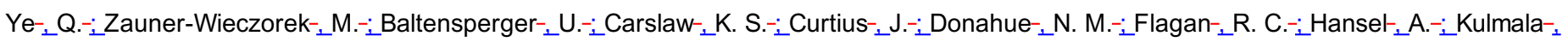

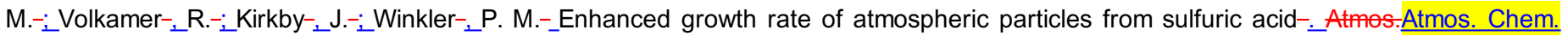
Phys. Discuss. Chem. Phys. Diseuss. 2019-_2019-_1-17. 10.5194/acp-2019-755.

61Smith- J. N.- Moore- K. F.- McMurry- P. H.- Eisele- F. L.- Atmospheric Measurements of Sub-20 nm Diameter Particle Chemical Composition by Thermal Desorption Chemical Ionization Mass Spectrometry- AAerosol Scienee and Technologyerosol Sci. Technol.- 2004- 38- 2- 100- 110- 10.1080/02786820490249036.

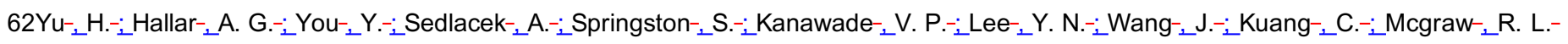
et al. Sub-3 nm Particles Observed at the Coastal and Continental Sites in the United States-. JJournal of Geophysieal Research: Atmospheres. Geophys. Res.: Atmos.- 2014-_119-2- 860- 879-_ 10.1002/2013JD020841.

63Boulon - J.- Sellegri- K.- Venzac - H.- Picard - D.- Weingartner- E.- Wehrle- G.- Collaud Coen- M.- BütikefefBütikofer- R.- FlüekigefFlückiger- E.- Baltensperger- U.- Laj- P.- New particle formation and ultrafine charged aerosol climatology at a high altitude site in the Alps (Jungfraujoch, $3580 \mathrm{~m}$ a.s.l., Switzerland)- AAtmospheric Chemistry and Physiestmos. Chem. Phys.- 2010- 10- 19- 9333- 9349- 10.5194/acp-10-9333-2010.

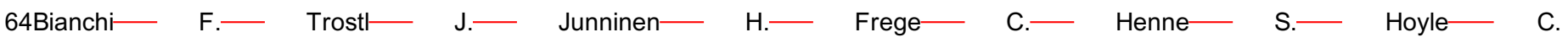
R.- Molteni- U.- Herrmann- E.- Adamov- A.- Bukowiecki- N.- Chen- X.- Duplissy- J.- Gysel- M.- Hutterli- M.- Kangasluoma- J.- Kontkanen- J.- Ku rten- A.- Manninen- H. E.- Munch- S.- Perakyla- O.- Petaja- T.- Rondo- L.- Williamson- C.- Weingartner- E.- Curtius- J.- Worsnop- D. R.- Kulmala- M.- Dommen- J.- Baltensperger- U.- New particle formation in the free troposphere: A question of chemistry and timing- Science Science- 2016- 352-6289-1109-121112- 10.1126/science.aad5456.

65Yu- H.- Ortega- J.- Smith- J. N.- Guenther- A. B.- Kanawade- V. P.- You- Y.- Liu- Y.- Hosman- K.- Karl- T.- Seco- R.- Geron- C.- Pallardy- S. G.- Gu- L.- MikkiläMikkilä- J.- Lee- S.-H.- New Particle Formation and Growth in an Isoprene-Dominated Ozark Forest: From Sub-5 nm to CCN-Active Sizes- AAerosol Seience and Technologyerosol Sci. Technol.- 2014- 48- 12- 1285- 1298- 10.1080/02786826.2014.984801.

66Vana- M.- Komsaare- K.- Hõrraketõrrak- U.- Mirme- S.- Nieminen- T.- Kontkanen- J.- Manninen- H. E.- PetäjäPetäjä- T.- Noe- S. M.- Kulmala- M.- Characteristics of new-particle formation at three SMEAR stations- Boreal Envirenment ResearchEnviron. Res.- 2016- 21- 3- 345- 362 
2 Seasonal characteristics of new particle formation and growth in 3 urban Beijing

4 Chenjuan Deng ${ }^{1}$, Yueyun $\mathrm{Fu}^{1}$, Lubna Dada ${ }^{2}$, Chao Yan ${ }^{2,3}$, Runlong Cai ${ }^{1}$, Dongsen Yang ${ }^{4}$, Ying

5 Zhou ${ }^{3}$, Rujing Yin ${ }^{1}$, Yiqun $\mathrm{Lu}^{5}$, Xiaoxiao Li ${ }^{1}$, Xiaohui Qiao ${ }^{1}$, Xiaolong Fan ${ }^{3}$, Wei Nie ${ }^{6}$, Jenni

6 Kontkanen ${ }^{2}$, Juha Kangasluoma ${ }^{2,3}$, Biwu Chu ${ }^{2,3}$, Aijun Ding ${ }^{6}$, Veli-Matti Kerminen ${ }^{2}$, Pauli

7 Paasonen ${ }^{2}$, Douglas R. Worsnop ${ }^{2,7}$, Federico Bianchi ${ }^{2}$, Yongchun Liu ${ }^{3}$, Jun Zheng ${ }^{4}$, Lin Wang ${ }^{5}$,

8 Markku Kulmala ${ }^{2,3, *}$, Jingkun Jiang ${ }^{1, *}$

$9{ }^{1}$ State Key Joint Laboratory of Environment Simulation and Pollution Control, School of

10 Environment, Tsinghua University, 100084 Beijing

112 Institute for Atmospheric and Earth System Research/Physics, Faculty of Science, University of

12 Helsinki, 00014 Helsinki, Finland

$13{ }^{3}$ Aerosol and Haze Laboratory, Beijing Advanced Innovation Center for Soft Matter Science and

14 Engineering, Beijing University of Chemical Technology, 100029 Beijing, China

$15{ }^{4}$ Collaborative Innovation Center of Atmospheric Environment and Equipment Technology,

16 Nanjing University of Information Science and Technology, 210044 Nanjing, China

$17{ }^{5}$ Shanghai Key Laboratory of Atmospheric Particle Pollution and Prevention (LAP3),

18 Department of Environmental Science and Engineering, Fudan University, Shanghai 200433,

19 China

$20{ }^{6}$ Joint International Research Laboratory of Atmospheric and Earth System Sciences, School of

21 Atmospheric Sciences, Nanjing University, 210023 Nanjing, China

$22 \quad{ }^{7}$ Aerodyne Research Inc., Billerica, Massachusetts 01821, USA

249 pages

$25 \quad 6$ figures 


\section{Classification of NPF days, non-NPF days and undefined days}
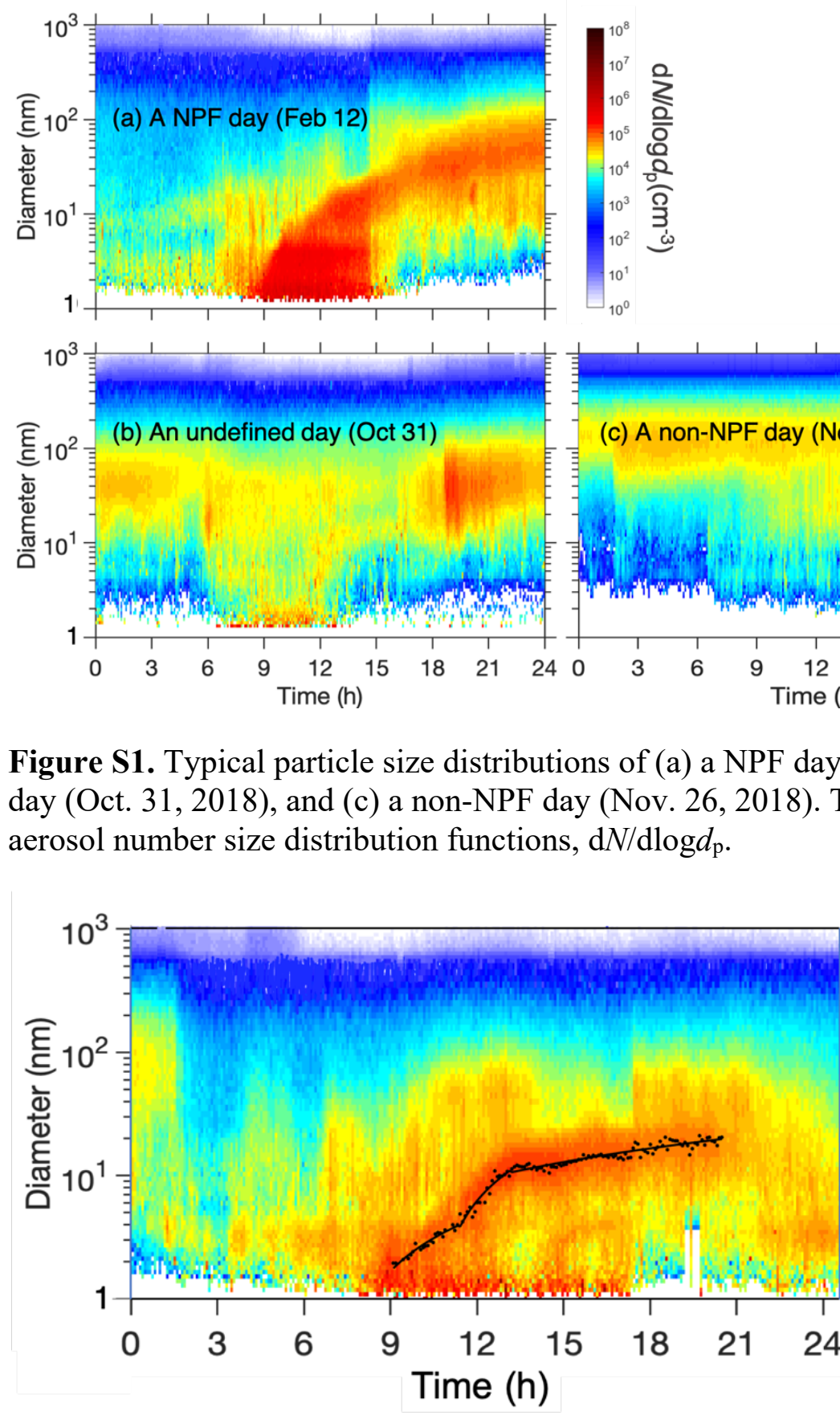
aerosol number size distribution functions, $\mathrm{d} N / \mathrm{d} \log d_{\mathrm{p}}$.

A typical NPF day is characterized as that there is a burst in the sub-3 nm particle number concentration $\left(\mathrm{N}_{\mathrm{sub}-3}\right)$ and subsequent growth of these newly formed particles (usually lasts for several hours), e.g., the event shown in Fig. S1(a). If the burst of sub-3 nm particles is not followed by further particle growth, the day is classified as an undefined day (e.g., Fig. S1(b)). When neither the burst of sub-3 nm particles nor the subsequent growth of newly formed particles were observed, it was classified into a non-NPF day (e.g., Fig. S1(c)).

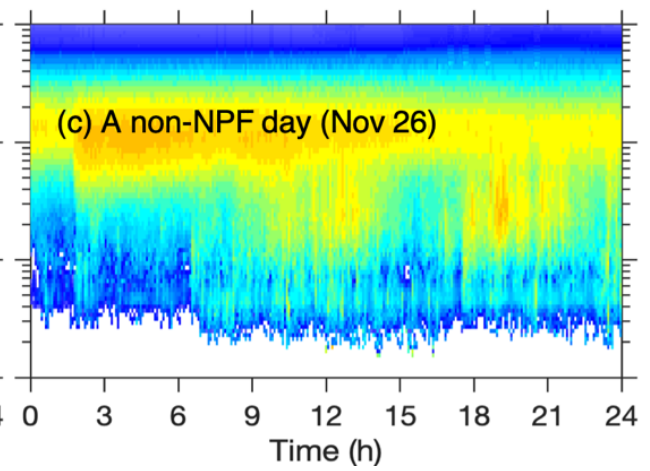

Figure S1. Typical particle size distributions of (a) a NPF day (Feb. 12, 2018), (b) an undefined day (Oct. 31, 2018), and (c) a non-NPF day (Nov. 26, 2018). The colored pixels represent

Figure S2. Lognormal fitting for estimating the observed growth rate on a NPF day (Feb. 14, 2018). Black dots are the representative diameter obtained through lognormal fitting to the measured aerosol size distributions during NPF periods. Black lines are obtained by linearly fitting the black dots. GR is calculated as the slope of the fitted black line, i.e., the gradient of the representative diameter as a function of time. 
45 The condensation sink (CS) characterizes the condensing vapor sink caused by pre-existing aerosols and can be calculated using the method reported in Kulmala et al. ${ }^{1}$,

$$
C S=2 \pi D \sum_{d_{\mathrm{p}}} \beta_{\mathrm{m}, d_{\mathrm{p}}} d_{\mathrm{p}} N_{d_{\mathrm{p}}}
$$

47 where $D$ is the diffusion coefficient of $\mathrm{H}_{2} \mathrm{SO}_{4}, \mathrm{~m}^{2} \cdot \mathrm{s}^{-1} ; d_{\mathrm{p}}$ is the particle geometric mean diameter for the size bin, $\mathrm{m} ; N_{d_{\mathrm{p}}}$ is the concentration of particles in the size bin, $\mathrm{m}^{-3} ; \beta_{\mathrm{m}}$ is the transition-regime correction factor ${ }^{2}$,

$$
\beta_{\mathrm{m}}=\frac{1+K_{n}}{1+1.677 K_{n}+1.333 K_{n}^{2}}
$$

where $K_{\mathrm{n}}$ is the Knudsen number, $K_{n}=2 \lambda / d_{\mathrm{p}}$.

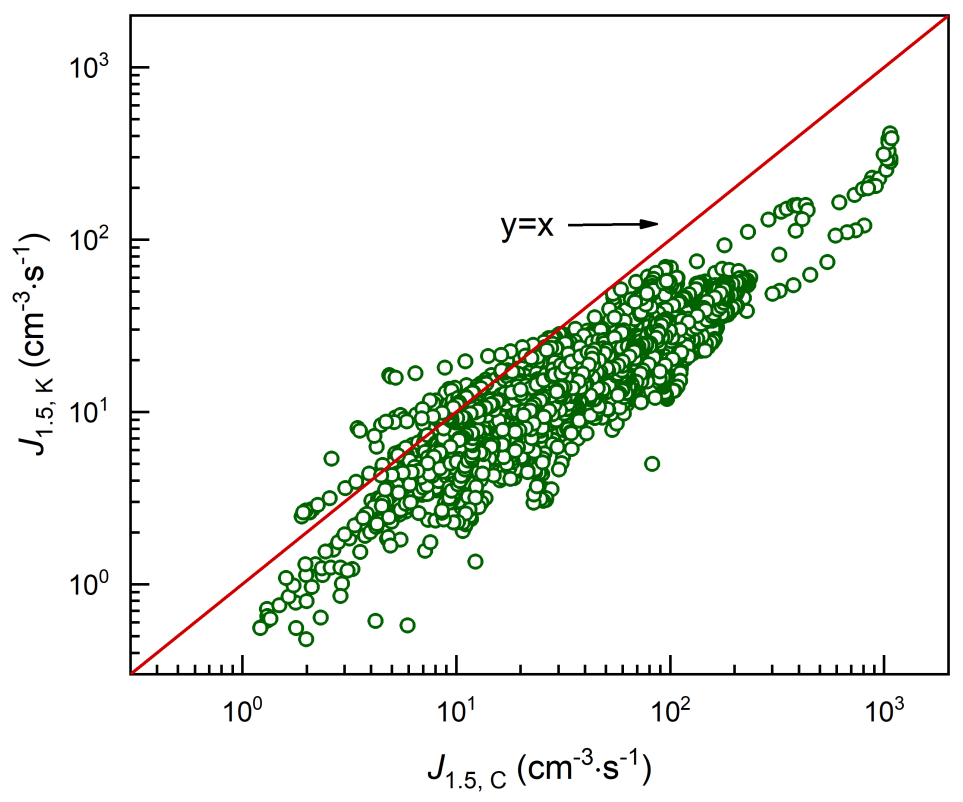

52 Figure S3. The formation rate of $1.5 \mathrm{~nm}$ particles estimated using two formulae, i.e., $J_{1.5, \mathrm{C}}$ and

$53 J_{1.5, \mathrm{~K}}$ were estimated using the equation (1) in Cai and Jiang ${ }^{3}$ and the equation (10) in Kulmala et 54 al. ${ }^{1}$, respectively. Note that the formula in Kulmala et al. ${ }^{1}$ was often used by previous studies to 55 estimate the formation rate in urban Beijing ${ }^{4,5}$.

\section{The indicator I for $\mathrm{H}_{2} \mathrm{SO}_{4}$-amine nucleation}

57 Derived from the kinetic model ${ }^{6}, I$ is an indicator to predict the occurrence of NPF dominated by $\mathrm{H}_{2} \mathrm{SO}_{4}$-amine nucleation. It is a simplified form of the modeled formation rate of $\mathrm{H}_{2} \mathrm{SO}_{4}$ tetramers (see the SI in Cai et al. ${ }^{6}$ ). Reasonable approximations were made when deriving this 60 indicator. Due to these approximations, $I$ can be considered as an empirical indicator instead of

61 the simulated formation rate. In urban Beijing, NPF days and non-NPF days can be well

62 distinguished using this indicator ${ }^{6}$. 
When estimating $I$ using Eq. (2), the evaporation rate of $\left(\mathrm{H}_{2} \mathrm{SO}_{4}\right)_{1}$ (amine $)_{1}$ cluster, $\gamma$, can be estimated from the collision rates and the Gibbs free energy of $\left(\mathrm{H}_{2} \mathrm{SO}_{4}\right)_{1}$ (amine $)_{1}$ formation ${ }^{6,7}$,

$$
\gamma(T)=\frac{\beta_{\mathrm{A}_{1} \mathrm{~B}_{1}} p}{k_{b} T} \exp \left\{\frac{\Delta_{\mathrm{f}} G_{m, \mathrm{~A}_{1} \mathrm{~B}_{1}}{ }^{\theta}(T)}{R T}\right\}
$$

where $\gamma(T)$ is the evaporate rate, $\mathrm{s}^{-1} ; \beta_{\mathrm{A}_{1} \mathrm{~B}_{1}}$ is the collision rate between the $\mathrm{H}_{2} \mathrm{SO}_{4}$ molecule and the amine molecule, $\mathrm{cm}^{-3} \cdot \mathrm{s}^{-1} ; p$ is the atmospheric pressure, $\mathrm{Pa} ; k_{\mathrm{b}}$ is the Boltzmann constant, $\mathrm{J} \cdot \mathrm{K}^{-1} ; T$ is the atmospheric temperature, $\mathrm{K} ; \mathrm{R}$ is the ideal gas constant, $\mathrm{J} \cdot \mathrm{mol}^{-1} \cdot \mathrm{K}^{-1}$;

$\Delta_{\mathrm{f}} G_{m, \mathrm{~A}_{1} \mathrm{~B}_{1}}{ }^{\theta}(T)$ is the molar Gibbs free energy of $\left(\mathrm{H}_{2} \mathrm{SO}_{4}\right)_{1}$ (amine) $)_{1}$ formation at temperature $T$, $\mathrm{J} \cdot \mathrm{mol}^{-1}$. It can be calculated from the standard molar free energy of formation of

$\left(\mathrm{H}_{2} \mathrm{SO}_{4}\right)_{1}$ (amine $)_{1}$ at $298.15 \mathrm{~K}$ as shown in Eq. S4,

$$
\frac{\Delta_{\mathrm{f}} G_{m, \mathrm{~A}_{1} \mathrm{~B}_{1}}{ }^{\theta}(T)}{T}=\frac{\Delta_{\mathrm{f}} G_{m, \mathrm{~A}_{1} \mathrm{~B}_{1}}{ }^{\theta}\left(T_{0}\right)}{T_{0}}-\int_{T_{0}}^{{ }^{T}} \frac{\Delta_{\mathrm{f}} H_{m}{ }^{\theta}}{T} \mathrm{~d} \bar{T}
$$

71

72

73

74

75

76

77

78

79

80

81

where $T_{0}=298.15 \mathrm{~K} ; \Delta_{\mathrm{f}} H_{m}{ }^{\theta}$ is the standard molar enthalpy of formation of $\left(\mathrm{H}_{2} \mathrm{SO}_{4}\right)_{1}$ (amine $)_{1}$, $\mathrm{J} \cdot \mathrm{mol}^{-1} ; \Delta_{\mathrm{f}} G_{m, \mathrm{~A}_{1} \mathrm{~B}_{1}}{ }^{\theta}\left(T_{0}\right)$ is assumed to be $-14.0 \mathrm{kcal} \cdot \mathrm{mol}^{-1}$ in this study, which is fitted to the measured data in urban Beijing in a previous study ${ }^{6}$. Note that although this value is close to the latest quantum chemistry calculation results ${ }^{8}$, there might be noticeable uncertainties in the calculated evaporation rates when $\mathrm{T}>300 \mathrm{~K}$ because of lacking experimental data.

When estimating $\beta$ and CS needed in Eq. (3) to calculate $\eta$, the enhancement factors of coagulation due to van der Waals forces were taken into account. They were estimated using the method from Chan and Mozurkewich ${ }^{9}$, which includes the effect of enhanced collision rates through van der Waals forces ${ }^{10,11}$. The Hamaker constant was assumed to be $6.4 \times 10-20 \mathrm{~J}^{12}$. The enhancement factors for $\beta$ and CS were estimated to be 2.3 and 1.3, respectively. The value of 2.3 has been shown to be consistent with the results obtained using atomistic simulation ${ }^{13}$.

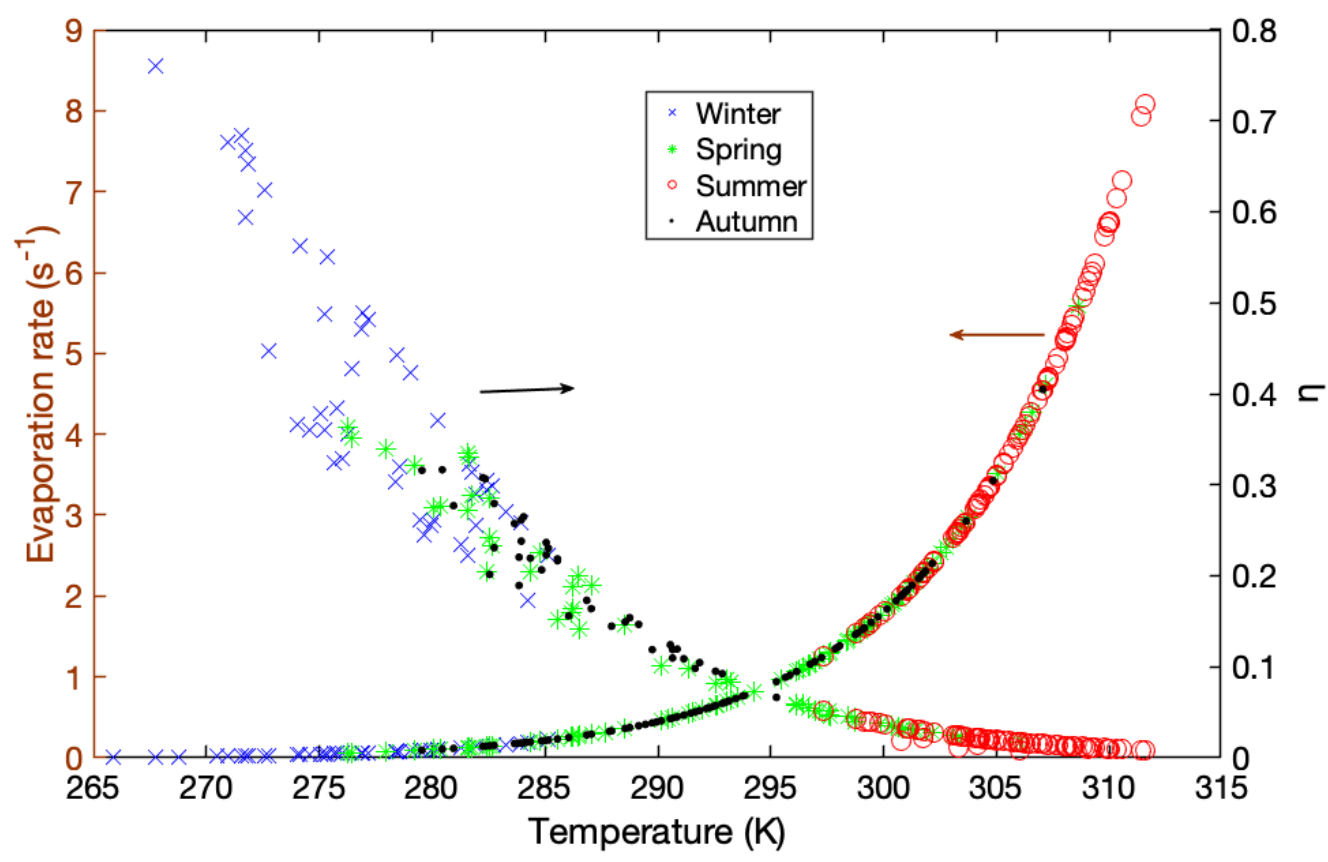

Figure S4. The evaporation rate (left) and the ratio of the $\left(\mathrm{H}_{2} \mathrm{SO}_{4}\right)_{1}$ (amine) $)_{1}$ cluster concentration to the total $\mathrm{H}_{2} \mathrm{SO}_{4}$ monomer concentration, $\eta$, as a function of atmospheric temperature in 
various seasons. Blue cross, green asterisk, red circle, and black dot markers represent data in winter, spring, summer, and autumn, respectively.

\section{The influence of seasonal variations of amine concentration}

A broad range of amines were measured using a modified Aerodyne high resolution time-offlight chemical ionization mass spectrometer (HR-ToF-CIMS) ${ }^{14}$. It also measures ammonia and amides. The ion chemistry is based on the proton-transfer reaction (PTR) between amines/ammonia and hydronium ions $\left(\mathrm{H}_{3} \mathrm{O}^{+} \cdot\left(\mathrm{H}_{2} \mathrm{O}\right)_{\mathrm{n}=0,1 . .)}\right.$. The construction, operation, and calibration of the instrument have been previously reported ${ }^{14}$. The concentrations of ammonia, three most abundant amines (methylamine (MA), dimethylamine (DMA), and trimethylamine (TMA)) and two amides were calibrated using a temperature-controlled U-shaped glass tube and the corresponding commercial permeation tubes. Note that the measured concentration of $\mathrm{C} 2$-amines was assumed to be the DMA concentration, which is most likely dominating in urban atmospheric environment over its isomer, ethylamine ${ }^{15}$.

Atmospheric amine concentrations in urban Beijing have not been reported before, and observations of amine concentrations are also limited in other atmospheric environments around the world ${ }^{16-20}$. In our studies, the concentrations of amines were continuously measured for approximately 5 months. DMA was the most abundant one, with a median concentration of 2.7 ppt. Due to its abundancy and strong ability to stabilize $\mathrm{H}_{2} \mathrm{SO}_{4}$ clusters, DMA was shown to be the major stabilizing species in urban Beijing ${ }^{6}$. Hence, when estimating the indicator $I$, "amine" represents DMA and its concentration was set to be the median value of $2.7 \mathrm{ppt}$.

If we categorized five-month data into different seasons, the median DMA concentration in autumn (Oct. 24, 2018 - Nov. 30, 2018), winter (Dec. 1, 2018 - Feb. 28, 2019) and spring (Mar. 1, 2019 - Mar. 13, 2019) were $\sim 4.1,1.5$, and $0.7 \mathrm{ppt}$, respectively. The range of 0.7-4.1 ppt was used to test the influence of amine concentration on the value of $I$. As shown in Fig. S5, the influence of amine concentration on $I$ is less significant than ambient temperature.

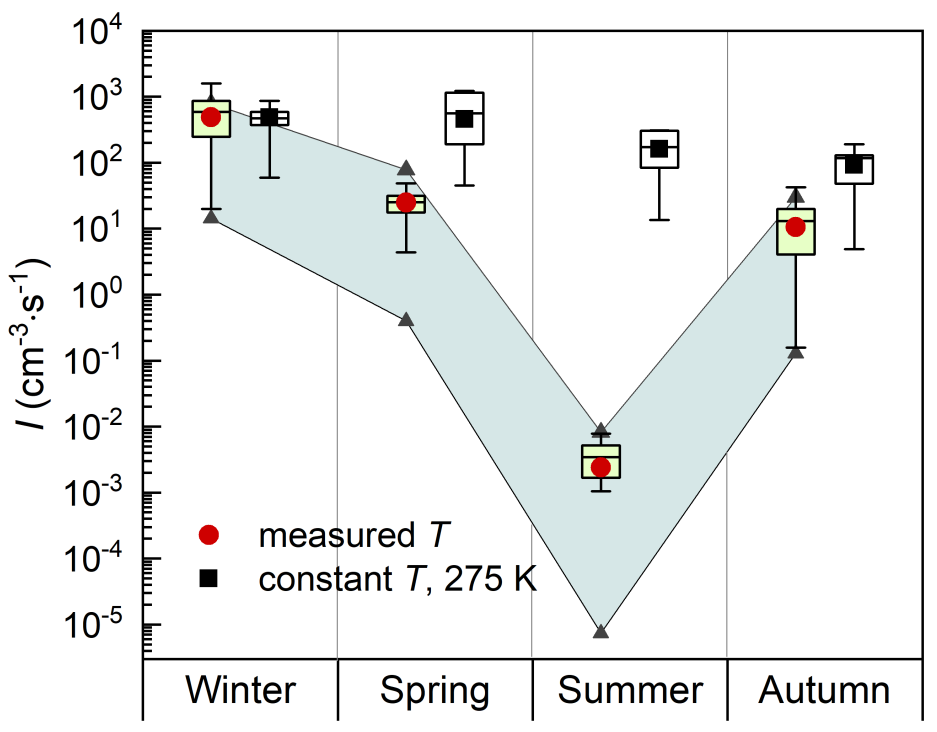

Figure S5. Seasonal variations of the indicator, $I$, estimated at a constant ambient temperature of $275 \mathrm{~K}$ and the measured ambient temperature during NPF periods, respectively. Daily maximum values for $I$ were used in this figure. The bottom and top edges of the box indicate the 25th and 75th percentiles, respectively. The black line inside the box represents the mean values. The dot, 
115 triangle and square markers indicate median values. The light blue shadow area represents the 116 variation range of $I$ values estimated with the amine concentration in the range of 0.7-4.1 ppt.

\section{5. Calculation of the calculated growth rate due to $\mathrm{H}_{2} \mathrm{SO}_{4}$ and clusters condensation}

118 The growth rate due to the condensation of species $\left(\mathrm{H}_{2} \mathrm{SO}_{4}\right.$ and $\left(\mathrm{H}_{2} \mathrm{SO}_{4}\right)_{n}(\text { amine })_{\mathrm{n}}$ clusters $(\mathrm{n} \leq$ 119 4)) can be calculated using the following equation,

$$
G R=k_{\text {coll }} C_{v}\left[\left(d_{p}{ }^{3}+d_{v}{ }^{3}\right)^{1 / 3}-d_{p}\right]
$$

$$
k_{\text {coll }}\left(d_{v}, d_{p}\right)=k_{K}\left(\sqrt{1+\left(\frac{k_{K}}{k_{D}}\right)^{2}}\right)-\frac{k_{K}}{k_{D}}
$$

where $d_{\mathrm{p}}$ and $d_{\mathrm{v}}$ represent the particle and vapor diameter, respectively, $\mathrm{m} ; k_{\text {coll }}$ represents the kinetic collision coefficient between particle and vapor, $\mathrm{m}^{3} \cdot \mathrm{s}^{-1} ; V_{\mathrm{v}}$ is the volume of vapor molecule, $\mathrm{m}^{3} ; C_{\mathrm{v}}$ is the concentration of condensing species, $\mathrm{m}^{-3}$. The concentrations of $\left(\mathrm{H}_{2} \mathrm{SO}_{4}\right)_{\mathrm{n}}(\text { amine })_{\mathrm{n}}$ clusters $(\mathrm{n} \leq 4)$ are derived using the simplified kinetic model in Cai et al. ${ }^{6}$. The accommodation coefficient is assumed to be unity. A collision enhancement of neutral vapors and particles due to attractive London-van-der-Waals forces is used when estimating $k_{\text {coll }}{ }^{9}$, 11

where $k_{\mathrm{K}}$ and $k_{\mathrm{D}}$ are the kinetic collision rates for the free molecule and continuum regime, respectively, and can be calculated as follows,

$$
\begin{gathered}
k_{K}=\frac{\pi}{8}\left(d_{v}+d_{p}\right)^{2}\left(\frac{8 k T}{\pi}\right)^{\frac{1}{2}}\left(\frac{1}{m_{v}}+\frac{1}{m_{p}}\right)^{\frac{1}{2}} E(\infty) \\
k_{D}=2 \pi\left(d_{v}+d_{p}\right)\left(D_{v}+D_{p}\right) E(0)
\end{gathered}
$$

where $\mathrm{m}_{\mathrm{v}}$ and $\mathrm{m}_{\mathrm{p}}$ are the mass of the single condensing species and particle, respectively, $\mathrm{kg} ; D_{\mathrm{v}}$ and $D_{\mathrm{p}}$ are diffusion coefficient of condensing species and particles, respectively, $\mathrm{m}^{2} \cdot \mathrm{s}^{-1} \cdot E(\infty)$ and $E(0)$ are collision enhancement factors due to London-van-der-Waals forces and can be 132 found in Chan and Mozurkewich ${ }^{9}$. 


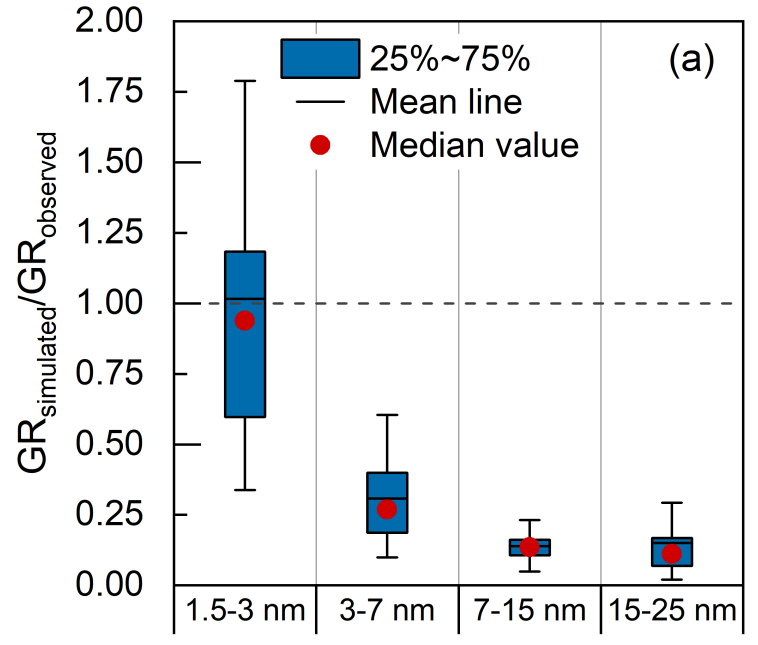

Size range

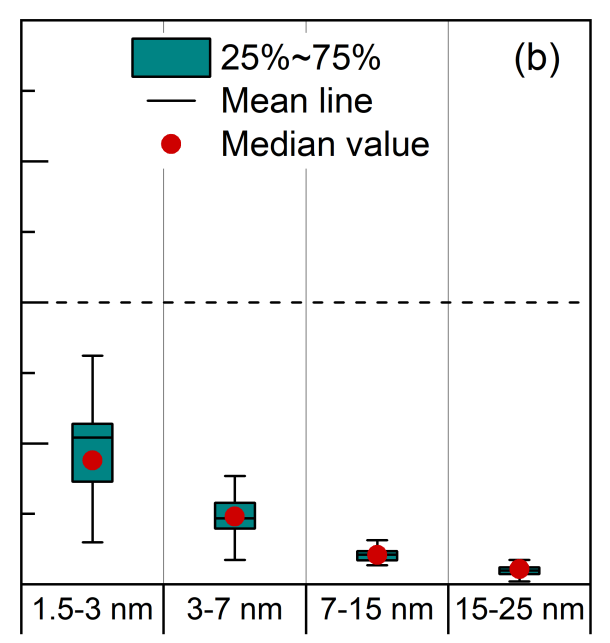

Size range

136 Figure S6. The ratio of the calculated growth rate (GR calculated) over the observed growth rate

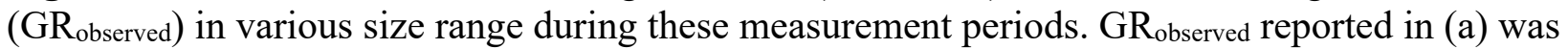
estimated using the log-normal distribution function method. $\mathrm{GR}_{\text {observed }}$ reported in (b) was estimated using the corrected appearance time method ${ }^{21}$ in (b), respectively. Their differences indicate the influences in the observed GR caused by the estimation methods. GR calculated $_{\text {a }}$ estimated using the condensation of $\mathrm{H}_{2} \mathrm{SO}_{4}$ and $\left(\mathrm{H}_{2} \mathrm{SO}_{4}\right)_{n}(\text { amine })_{\mathrm{n}}$ clusters $(\mathrm{n} \leq 4)$. The geometric mean value of $\mathrm{GR}_{\text {calculated }}$ in each size rage was used to calculate the ratio of $\mathrm{GR}_{\text {calculated }} / \mathrm{GR}_{\text {observed. }}$ The bottom and top edges of the box indicate the 25 th and 75 th percentiles, respectively. The black line inside the box represents the mean values. The dot and square markers indicate median values.

\section{Reference}

$148 \quad$ 1. Kulmala, M.; Petaja, T.; Nieminen, T.; Sipila, M.; Manninen, H. E.; Lehtipalo, K.; Dal 149 Maso, M.; Aalto, P. P.; Junninen, H.; Paasonen, P.; Riipinen, I.; Lehtinen, K. E.; Laaksonen, A.; 150 Kerminen, V. M., Measurement of the nucleation of atmospheric aerosol particles. Nat Protoc 2012, 7, (9), 1651-67.

152 2. Fuchs, N. A.; Sutugin, A. G., HIGH-DISPERSED AEROSOLS. In Topics in Current 153 Aerosol Research, Hidy, G. M.; Brock, J. R., Eds. Pergamon: 1971; p 1.

154 3. Cai, R.; Jiang, J., A new balance formula to estimate new particle formation rate: 155 reevaluating the effect of coagulation scavenging. Atmospheric Chemistry and Physics 2017, 17, 156 (20), 12659-12675.

157 4. Wu, Z.; Hu, M.; Liu, S.; Wehner, B.; Bauer, S.; Ma ßling, A.; Wiedensohler, A.; Petäjä, 158 T.; Dal Maso, M.; Kulmala, M., New particle formation in Beijing, China: Statistical analysis of 159 a 1-year data set. Journal of Geophysical Research 2007, 112, (D9), D09209.

160 5. Wang, Z. B.; Hu, M.; Sun, J. Y.; Wu, Z. J.; Yue, D. L.; Shen, X. J.; Zhang, Y. M.; Pei, X. 161 Y.; Cheng, Y. F.; Wiedensohler, A., Characteristics of regional new particle formation in urban 162 and regional background environments in the North China Plain. Atmospheric Chemistry and 163 Physics 2013, 13, (24), 12495-12506.

164 6. $\quad$ Cai, R.; Yan, C.; Yang, D.; Yin, R.; Lu, Y.; Deng, C.; Fu, Y.; Ruan, J.; Li, X.;

165 Kontkanen, J.; Zhang, Q.; Kangasluoma, J.; Ma, Y.; Hao, J.; Worsnop, D. R.; Bianchi, F.;

166 Paasonen, P.; Kerminen, V. M.; Liu, Y.; Wang, L.; Zheng, J.; Kulmala, M.; Jiang, J., Sulfuric 167 acid-amine nucleation in the urban atmospheric environment. 2020. (under review).

1687 7. McGrath, M. J.; Olenius, T.; Ortega, I. K.; Loukonen, V.; Paasonen, P.; Kurtén, T.; 169 Kulmala, M.; Vehkamäki, H., Atmospheric Cluster Dynamics Code: a flexible method for 
solution of the birth-death equations. Atmospheric Chemistry and Physics 2012, 12, (5), 23452355 .

8. Myllys, N.; Chee, S.; Olenius, T.; Lawler, M.; Smith, J. J. T. J. o. P. C. A., MolecularLevel Understanding of Synergistic Effects in Sulfuric Acid-Amine-Ammonia Mixed Clusters. 2019, 123, (12), 2420-2425.

9. Chan, T. W.; Mozurkewich, M. J. J. o. a. s., Measurement of the coagulation rate constant for sulfuric acid particles as a function of particle size using tandem differential mobility analysis. 2001, 32, (3), 321-339.

178 10. Kürten, A.; Li, C.; Bianchi, F.; Curtius, J.; Dias, A.; Donahue, N. M.; Duplissy, J.; Flagan, R. C.; Hakala, J.; Jokinen, T.; Kirkby, J.; Kulmala, M.; Laaksonen, A.; Lehtipalo, K.; Makhmutov, V.; Onnela, A.; Rissanen, M. P.; Simon, M.; Sipilä, M.; Stozhkov, Y.; Tröstl, J.; Ye, P.; McMurry, P. H., New particle formation in the sulfuric acid-dimethylamine-water system: reevaluation of CLOUD chamber measurements and comparison to an aerosol nucleation and growth model. Atmospheric Chemistry and Physics 2018, 18, (2), 845-863. 11. Stolzenburg, D.; Simon, M.; Ranjithkumar, A.; Kürten, A.; Lehtipalo, K.; Gordon, H.; Nieminen, T.; Pichelstorfer, L.; He, X. C.; Brilke, S.; Xiao, M.; Amorim, A.; Baalbaki, R.; Baccarini, A.; Beck, L.; Bräkling, S.; Caudillo Murillo, L.; Chen, D.; Chu, B.; Dada, L.; Dias, A.; Dommen, J.; Duplissy, J.; El Haddad, I.; Finkenzeller, H.; Fischer, L.; Gonzalez Carracedo, L.; Heinritzi, M.; Kim, C.; Koenig, T. K.; Kong, W.; Lamkaddam, H.; Lee, C. P.; Leiminger, M.; Li, Z.; Makhmutov, V.; Manninen, H. E.; Marie, G.; Marten, R.; Müller, T.; Nie, W.; Partoll, E.; Petäjä, T.; Pfeifer, J.; Philippov, M.; Rissanen, M. P.; Rörup, B.; Schobesberger, S.; A.; Vazquez-Pufleau, M.; Wagner, A. C.; Wang, M.; Wang, Y.; Weber, S. K.; Wimmer, D.; Wlasits, P. J.; Wu, Y.; Ye, Q.; Zauner-Wieczorek, M.; Baltensperger, U.; Carslaw, K. S.; Curtius, J.; Donahue, N. M.; Flagan, R. C.; Hansel, A.; Kulmala, M.; Volkamer, R.; Kirkby, J.; Winkler, P. M., Enhanced growth rate of atmospheric particles from sulfuric acid. Atmos. Chem. Phys. Discuss. 2019, 2019, 1-17.

12. Hamaker, H. C., The London—van der Waals attraction between spherical particles. Physica 1937, 4, (10), 1058-1072.

13. Halonen, R.; Zapadinsky, E.; Kurtén, T.; Vehkamäki, H.; Reischl, B., Rate enhancement in collisions of sulfuric acid molecules due to long-range intermolecular forces. Atmospheric Chemistry and Physics 2019, 19, (21), 13355-13366.

14. Zheng, J.; Ma, Y.; Chen, M.; Zhang, Q.; Wang, L.; Khalizov, A. F.; Yao, L.; Wang, Z.; Wang, X.; Chen, L., Measurement of atmospheric amines and ammonia using the high resolution time-of-flight chemical ionization mass spectrometry. Atmospheric Environment 2015, 102, 249259 .

15. VandenBoer, T. C.; Petroff, A.; Markovic, M. Z.; Murphy, J. G., Size distribution of alkyl amines in continental particulate matter and their online detection in the gas and particle phase. Atmospheric Chemistry and Physics 2011, 11, (9), 4319-4332.

16. Ge, X.; Wexler, A. S.; Clegg, S. L., Atmospheric amines - Part I. A review. Atmospheric Environment 2011, 45, (3), 524-546.

17. Grönberg, L.; Lövkvist, P.; Jönsson, J. Å., Measurement of aliphatic amines in ambient air and rainwater. Chemosphere 1992, 24, (10), 1533-1540.

18. Hanson, D. R.; McMurry, P. H.; Jiang, J.; Tanner, D.; Huey, L. G., Ambient Pressure Proton Transfer Mass Spectrometry: Detection of Amines and Ammonia. Environmental Science \& Technology 2011, 45, (20), 8881-8888.

19. Yu, H.; Lee, S.-H., Chemical ionisation mass spectrometry for the measurement of atmospheric amines. Environmental Chemistry 2012, 9, (3).

20. You, Y.; Kanawade, V. P.; de Gouw, J. A.; Guenther, A. B.; Madronich, S.; SierraHernández, M. R.; Lawler, M.; Smith, J. N.; Takahama, S.; Ruggeri, G.; Koss, A.; Olson, K.; Baumann, K.; Weber, R. J.; Nenes, A.; Guo, H.; Edgerton, E. S.; Porcelli, L.; Brune, W. H.; Goldstein, A. H.; Lee, S. H., Atmospheric amines and ammonia measured with a chemical 
222 ionization mass spectrometer (CIMS). Atmospheric Chemistry and Physics 2014, 14, (22), 223 12181-12194.

224 21. Cai, R.; Li, C.; He, X. C.; Deng, C.; Lu, Y.; Yin, R.; Yan, C.; Wang, L.; Jiang, J.;

225 Kulmala, M.; Kangasluoma, J., Impacts of coagulation on the appearance time method for sub-3 $226 \mathrm{~nm}$ particle growth rate evaluation and their corrections. Atmos. Chem. Phys. Discuss. 2020, $2272020,1-24$. 